\title{
1 What can cetacean stranding records tell us? A study of UK and Irish cetacean 2 diversity over the past 100 years
}

4 Ellen J. Coombs ${ }^{1,2^{*}}$, Rob Deaville ${ }^{3}$, Richard C. Sabin ${ }^{2}$, Louise Allan², Mick O'Connell ${ }^{4}$, Simon 5 Berrow $^{4,5}$, Brian Smith ${ }^{2}$, Andrew Brownlow ${ }^{6}$, Mariel Ten Doeschate ${ }^{6}$, Rod Penrose ${ }^{7}$, Ruth

6 Williams $^{8}$, Matthew W. Perkins ${ }^{3}$, Paul D. Jepson ${ }^{3}$ and Natalie Cooper ${ }^{2}$

1 University College London, Genetics, Evolution and Environment Department, Gower Street, WC1E 6BT, UK 102 Department of Life Sciences, Natural History Museum, London, Cromwell Road, London, SW7 5BD. UK.

113 UK Cetacean Strandings Investigation Programme, The Wellcome Building, Institute of Zoology, Zoological

12 Society of London, Regent's Park, London NW1 4RY. UK.

134 Irish Whale and Dolphin Group, Merchants Quay, Kilrush V15 E762, County Clare, Ireland

145 Marine and Freshwater Research Centre, Galway-Mayo Institute of Technology, Dublin Road, Galway H91

15 T8NW, Ireland.

166 Scottish Marine Mammal Stranding Scheme, SRUC Wildlife Unit, Drummondhill, Inverness, IV2 4JZ

177 Marine Environmental Monitoring, Penwalk, Llechryd, Cardigan, West Wales SA43 2PS

188 Cornwall Wildlife Trust, Five Acres, Allet, Truro, TR4 9DJI, UK 


\section{Abstract}

40 There are many factors that may explain why cetaceans (whales, dolphins, and porpoises)

41 strand. Around the UK and Ireland, over 20,000 stranding records have been collected since

421913 , resulting in one of the longest, continuous, systematic stranding data sets in the world.

43 We use this dataset to investigate temporal and spatial trends in cetacean strandings and use generalized additive models (GAMs) to investigate correlates of strandings. We find a dramatic increase in strandings since the 1980s, most likely due to increases in recording effort, and the formation of formal strandings networks. We found no correlation between the numbers of cetaceans stranding each year and several potential environmental and anthropogenic predictors: storms, geomagnetic activity, North Atlantic Oscillations, seasurface temperature, and fishing catch. We suggest that this is because the scale of change in the variables is too coarse to detect any potential correlations. It may also highlight the idiosyncratic nature of species' responses to external pressures, and further the need to

52 investigate other potential correlates of strandings, such as bycatch and military sonar.

53 Long-term cetacean stranding data provide vital information on past and present diversity for 54 common, rare, and inconspicuous species. This study underlines the importance of 55 continued support for stranding networks. 
65 Cetaceans (whales, dolphins, and porpoises) are major components of oceanic ecosystems 66 (Roman et al. 2014). They are top predators and their distributions can provide an indication 67 of prey abundance and wider ocean health (Friedlaender et al. 2006, Burek et al. 2008, 68 Roman et al. 2014). Unfortunately, many cetacean species are threatened (Reeves et al. 69 2003, IUCN SSC, 2018) and are vulnerable to anthropogenic impacts, such as incidental 70 entanglement in fishing gear (bycatch), ship strikes, hunting, chemical or noise pollution and 71 environmental changes across their ranges (Parsons et al. 2010, Ramp et al. 2015). It is 72 therefore important to monitor cetaceans to determine the impacts of these pressures on 73 their abundance and behavior (Bejder et al. 2006). As with other marine species, cetaceans can prove difficult to study as they are often wide-ranging and spend most of their lives submerged under water (Evans and Hammond, 2004). Frequently employed monitoring techniques, such as surveying from boats, are not only expensive and time consuming, but are often biased towards conspicuous species or those that respond positively to boat presence, such as bottlenose dolphins (Tursiops truncatus) and short-beaked common dolphins (Delphinus delphis; Evans and Hammond, 2004). One approach to these constraints is to use strandings data, i.e., records of cetaceans that have washed ashore.

81

Stranding records are the primary source of information for many elusive species, such as beaked whales (Ziphiidae; Morin et al. 2017) and can provide an indication of relative abundance and richness in extant cetacean communities (Evans and Hammond, 2004, Maldini et al. 2005, Pyenson, 2011). Globally, there are several long-term, regional stranding datasets: the northwest Pacific USA, e.g., Norman et al. (2004) who reported 904 records, concluding that most reports are made in summer time when sampling effort is higher; Hawaii, e.g., Maldini et al. (2005); who documented 202 odontocete strandings; the Netherlands, e.g., Murphy et al. (2006) who have $\sim 10,000$ strandings records to date, the 90 majority of which are harbor porpoises; and Australia, e.g., Evans et al. (2005), who 91 analyzed 639 stranding events comprising 39 taxonomic groups. The Australian dataset only 
92 has 21 records gathered prior to 1960 (Lloyd and Ross, 2015), while the Hawaiian and North

93 American datasets have limited accuracy prior to the 1960s and 70s when systematic

94 recording of strandings became more standardized (Pyenson, 2010). The Dutch dataset has 95 systematic records dating back to at least the 1920s (Murphy et al. 2006), with some records dating back hundreds of years. Similarly, the Irish Whale and Dolphin Group (IWDG) stranding records date back to the $18^{\text {th }}$ Century. Although globally there are several longterm stranding datasets the majority of them are not systematic, nor as long-term as the one we present here. The Natural History Museum, London (NHM) has maintained a database of UK strandings since 1913, making it one of the longest, continuous, systematic cetacean stranding datasets in the world (NHM, 2018). The program became part of the Cetacean Strandings Investigation Programme (CSIP) in 1990, which continues to record cetacean strandings in the UK to the present day and investigates the causes of strandings through systematic postmortem examinations, under contract to the UK government (CSIP, 2019).

105 The IWDG has been systematically recording strandings since 1990 (IWDG, 2019).

106 Despite records being available up to 2015, no comprehensive studies of temporal changes 107 in cetacean strandings exist for this full time period, i.e., from 1913-2015. The unique 108 characteristics of this data set are ideal for investigating trends and inter-annual variability in cetaceans strandings alongside anthropogenic and/or environmental changes.

110 
121 Many studies have investigated possible causes of cetacean strandings. Strandings may be

122 triggered by geomagnetic storms affecting the orientation of cetaceans that navigate by

123 these means (Vanselow et al. 2017). Other (i.e., meteorological) storms may exhaust,

124 displace, or physically injure cetaceans, increasing the risk of disorientation and stranding

125 (Mignucci-Giannoni et al. 2000, Bogomolni et al. 2010, Schumann et al. 2013). Fluctuations

126 in the North Atlantic Oscillation (NAO) can lead to storms and wind and sea surface

127 temperature (SST) changes, that may in turn influence prey abundance and distributions

128 (Hurrell, 1995, Pierce et al. 2007) that can alter cetacean distributions and lead to strandings

129 (Simmonds and Eliott, 2009, Schumann et al. 2013). Anthropogenic impacts such as military sonar can cause cetaceans to surface quickly resulting in fatal decompression sickness

131 (Jepson et al. 2003). Further, direct physical contact with ships (i.e., ship strike) (Laist et al.

132 2001) has also been attributed to deaths in a number of stranding records. Starvation is a 133 known cause of death recorded in stranding necropsies (Leeney et al. 2008, Deaville et al.

134 2015), which may be linked to overfishing. Other effects of human fishing efforts e.g.,

135 bycatch, are well documented (Read et al. 2017). Entanglement in fisheries nets, and other commercial debris (Leeney et al. 2008, Deaville et al. 2015) causes either immediate asphyxiation (often the case in smaller cetaceans) or exaggerated energy expenditure from the drag of nets, often leading to emaciation and asphyxiation (Moore and van Der Hoop, 2012). Pollution and plastic contamination have also been attributed to cetacean death and subsequent stranding (Simmonds, 2012).

Our overall objective is to explore broad-scale patterns and correlates of cetacean strandings through time. Combining all three datasets for the first time, we present over 100 years of data, and show spatio-temporal patterns in the number of individuals stranding in

145 the UK and Ireland. We also used Generalized Additive Models (GAMs) to explore 146 correlates of strandings. 


\section{Methods}

\section{Study area}

150 All stranding records were recorded from UK and Irish coastlines between $49^{\circ} \mathrm{N}$ and $61^{\circ} \mathrm{N}$,

151 and $11^{\circ} \mathrm{W}$ and $3^{\circ} \mathrm{E}$. The predominant ocean current in this region is the North Atlantic drift,

152 which travels eastwards with prevailing winds towards the western UK and Ireland. Further, 153 there are powerful currents associated with submarine canyons to the extreme southwest of 154 the UK, near the edge of the continental shelf. Bed stress (disturbance to the sea floor by 155 tidal currents) is lowest in the more sheltered, shallower waters of the Irish sea, English 156 Channel, and the southern North Sea, near East Anglia (Connor et al. 2006). The UK 157 continental shelf includes parts of the North Sea, Irish Sea, English Channel, and North

158 Atlantic, and is under $200 \mathrm{~m}$ deep around most of the UK. This continental shelf slopes down 159 into a deep-sea zone off the west coast of Ireland (Connor et al. 2006).

160

\section{Strandings datasets}

162 During the early $20^{\text {th }}$ century most UK stranding reports were sent to the NHM by HM

163 Coastguard. Information was collected via standardized forms that showed the basic data

164 requirements. Members of the public also submitted reports via the coastguard. As

165 photography became more widely used, more reports to the NHM were supported by 166 images. With the development of Wildlife Trusts around the UK, wardens, officers, and 167 rangers became key reporters of strandings. When CSIP and the IWGD were set up in 1990, wider publicity was given to the work on strandings, raising public awareness and understanding. Reporting strandings via online forms, telephone, and social media became

170 common practice and is still used today. Many reported strandings are attended by the CSIP 171 and IWDG teams.

173 We used stranding data from the NHM, CSIP and IWDG to investigate temporal and spatial 174 patterns of cetacean strandings around the UK and Ireland. In the present study, a stranding 
175 is defined as any individual found beached or washed up onto land (beaches, mudflats,

176 sandbanks etc.) either alive or dead, and also includes a small number of records where the

177 individual was re-floated. All three datasets contain information on the stranded species, the

178 date it was discovered, the latitude and longitude of the stranding location, and whether the

179 animal was alive or dead on discovery. For some specimens, the NHM and CSIP datasets

180 also have information on whether the individual stranded alone or with others of the same

181 species (a mass stranding, i.e., more than one individual, excluding mother-calf pairs), the

182 decomposition condition of the carcass, sex, and body length. The NHM dataset contains

1834,311 UK and Irish stranding records from 1913-1989 (NHM, 2018). The CSIP dataset

184 contains 13,084 UK, and seven Irish stranding records from 1990-2015 (CSIP, 2018), and

185 the IWDG dataset contains 2,973 Irish cetacean records for the period 1913-2015 (IWDG,

186 2018). We combined the datasets and removed 220 duplicate records found in both the

187 NHM and IWDG datasets.

188

189 Before analyses, we cleaned the data by removing any records where species were listed as 190 'unknown', ‘unknown cetacean', or similar. Then we removed any species that are rarely 191 seen in UK waters, defined using Reid et al. (2003) and OBIS-SEAMAP (Halpin et al. 2009);

192 Supplemental information: Table S1, S2). These are likely to represent one-off events that

193 will not contribute to general patterns, or may be misidentifications, especially in the

194 historical data. These species were: narwhal (Monodon monoceros), beluga (Delphinapterus 195 leucas), dwarf sperm whale (Kogia sima), Blainville's beaked whale (Mesoplodon

196 densirostris), Gervais' beaked whale (Mesoplodon europaeus), Fraser's dolphin

197 (Lagenodelphis hosei), and melon-headed whale (Peponocephala electra). Where possible, 198 we converted grid references and detailed location descriptions into latitudes and longitudes 199 for records that did not have this information. We sense-checked all anomalous strandings, 200 such as those with localities far inland, and removed any that were not near a viable water 201 source. Lastly, we standardized the date formats and scientific names across the combined 
202 dataset, using YYYY-MM-DD for dates and the taxonomy of Reid et al. (2003) for scientific

203 names.

204

\section{Correlates of strandings through time}

206 We plotted changes in the total number of stranded individuals through time for all species 207 combined, for each species separately, and for mysticetes (baleen whales) and odontocetes 208 (toothed whales). Next, we explored the spatio-temporal patterns in strandings for all 209 species combined, and for mysticetes and odontocetes separately, across the UK and 210 Ireland at 25-year intervals and decadal intervals (Fig. S3).

212 We considered drivers of changes in strandings through time. We fitted models of numbers 213 of individuals stranded against various predictor variables thought to correlate with cetacean 214 strandings (Table 1, Fig.1). We included the following predictors because they have been 215 reported to potentially influence strandings, and because we could collate data for them on a 216 yearly basis for the UK and Ireland for the full-time span of our dataset (1913-2015)

217 (Supplemental information: Data Collection). (1) Geomagnetic activity. Some cetaceans, 218 such as sperm whales (Physeter macrocephalus) may use Earth's geomagnetic fields for 219 navigation (Kirschvink et al. 1986, Kremers et al. 2014, Vanselow et al. 2017), thus changes 220 in geomagnetic activity, e.g., solar storms, may affect their navigation and increase the 221 likelihood of strandings (Vanselow et al. 2017). (2) Sea surface temperature (SST). 222 Changes in SST $\left({ }^{\circ} \mathrm{C}\right)$ can affect prey abundance, resulting in net movements of cetaceans 223 as they follow their prey (Pierce et al. 2007, Simmonds and Eliott, 2009), which could result 224 in changes in cetacean distribution and therefore the spatial distribution of strandings. (3) 225 Storm events. Storm conditions, hurricane events and associated oceanographic disturbances may increase strandings (Mignucci-Giannoni et al. 2000, MacLeod et al. 2004,

227 Bogomolni et al. 2010) as individuals suffer from exhaustion, disorientation, or direct 228 physical injury. Further, these impacts can also affect food sources (Lawler et al. 2007, 229 Evans et al. 2005), which may alter cetacean distributions and therefore the likelihood of 
230 strandings. (4) North Atlantic Oscillations (NAO). Fluctuations in the NAO can affect prey

231 distribution and abundance via associated wind and temperature changes (Hurrell, 1995,

232 Pierce et al. 2007). Low NAO indexes have been associated with physiological stress in

233 North Atlantic right whales (Eubalaena glacialis). Note that although NAO and storms, and

234 NAO and SST are related, they are not strongly correlated $\left(r^{2}<0.16\right.$ and $r^{2}<0.001$

235 respectively; Supplemental information; Environmental variables). Therefore, we included all

236 three variables. (5) Fishing catch. Over-fishing can have a direct impact on cetaceans due

237 to a reduction of their prey (Evans, 1990, Weir et al. 2007), causing starvation, or a shift in

238 cetacean distribution as they search for prey elsewhere. Further, discarded or fixed fishing

239 nets and creel lines are partly responsible for cetacean mortality as bycatch (Leeney et al.

240 2008). Note that ideally, we would have included sonar use, bycatch, and chemical

241 pollution, but none of these variables were available for every year in our dataset (i.e., 1913

242 - 2015), particularly for the historical data. We ran a model that included a proxy for shipping

243 traffic, but these data were only available for 1950-2015 (Supplemental Information;

244 Shipping model). Sources and units of the main model dataset are in Table 1.

245

$246<$ Table 1>

$247<$ Figure 1>

248

249

250

251

252

253 
255 We modelled the effects of our predictors on the number of individuals stranded using

256 GAMs. GAMs allow for smooth relationships between multiple explanatory variables and the 257 response variable (Wood, 2017). Like generalized linear models (GLMs), GAMs use a link

258 function. GAMs use this link function to establish a relationship between a 'smoothed'

259 function of the predictor variable(s) and the mean of the response variable (Guisan et al.

260 2002). A GAM is substantially more flexible because the relationships between independent

261 and dependent variables are not assumed to be linear (Wood, 2017). Our initial data

262 exploration found that relationships between the individual predictors and the number of 263 individuals stranded were nonlinear.

264 We modelled the total number of stranded individuals as a sum of smooth functions of 265 covariates in a GAM framework (1). In an attempt to account for changes in the potential for 266 detection of stranded cetaceans through time we included yearly UK population size based 267 on the assumption that as population size increases, or activity in an area increases, it is 268 more likely that strandings will be observed and reported (Norman et al. 2004, Maldini et al. 2005, Pyenson, 2011, McGovern et al. 2016). Stranding studies highlight the importance of considering population growth as a proxy for observer effort (Maldini et al. 2005, Pyenson, 2011). However, it is often difficult to obtain accurate population estimates over the time

272 frame of these stranding databases or in regions where populations have varied 273 considerably (e.g., the Hawaiian Islands, Maldini et al. 2005)., we used yearly UK human 274 population size (Table 1) as an offset in the model. To further investigate the impacts of 275 sampling effort, we ran two case study models that look at differences in population between 276 the populated southern UK, and the less populated northern UK (Supplemental information; 277 Regional study 1 \& 2). Smooths were modelled using a thin plate spline basis with shrinkage 278 (Marra and Wood, 2011), which allowed terms to be removed from the model (i.e., their 279 effect size shrunk to zero) during fitting, thus terms were selected during model fitting. As we 280 wanted to model species-specific effects, we included a factor-smooth interaction between 
281 year of stranding and species; this term fitted a smooth of time for each species but allowed

282 common smooths to be fitted for the other covariates. An advantage of this approach is that

283 the per-species smooths are estimated as deviations from a base-level smooth, so some

284 information is shared between species. We fitted models with the following candidate

285 response count distributions: Poisson, quasi-Poisson, negative binomial, and Tweedie. We

286 used standard residual checks for GAMs (Q-Q plot, histogram of residuals, residuals vs.

287 linear predictors, response vs. fitted values) to decide between response distributions and

288 assess model fit. We report the results using the negative binomial distribution as this was

289 the best fit for the data (Supplemental information: GAM candidate response distributions)

290 with each of the different response distributions (Supplemental information: Fig. S7:S10).

291 The total number of stranded individuals was modelled as a sum of smooth functions of the $k$ explanatory variables $z_{t k}$ using a GAM with the general formulation:

293

(1)

294

$$
s_{t, \text { species }}=\exp \left[\log \left(p_{t}\right)+\beta_{0}+\sum_{k=1}^{K} f_{k}\left(z_{t k}\right)+f_{t, \text { species }}(t, \text { species })\right]
$$

295

Where $s \sim$ negative binomial $(\theta), s$ is the number of stranded individuals, $t$ is year, species is the cetacean species in the stranding dataset, $p$ is an offset of human population size, $\beta_{0}$ is the intercept and $f_{k}$ are smooths of the $\mathrm{K}$ explanatory variables. The explanatory variables for inclusion in the models were smooth functions of year, with the additional species smooth as mentioned and shown in (1), and storm events, geomagnetic activity, sea surface temperature, North Atlantic oscillation, and fishing catch.

302

303 We fitted models using Restricted Maximum Likelihood (REML) in the R mgcv package version 1.8.17 (Wood, 2011). REML was preferable because when models contain highly correlated covariates, REML finds an optimal degree of smoothing (Reiss and Ogden 2009).

306 In a GAM, $\mathrm{k}$ is the maximum complexity of the basis used to represent the smooth term. If 307 the $\mathrm{k}$ value is high enough, we can be sure that there is enough flexibility in the model. We 
308 can find out if $k$ is high enough by increasing the $k$ value and refitting the original model

309 (Supplemental information: Setting the k parameter). After refitting the model and analyzing

310 the GAM output, we set the k parameter for storm events and geomagnetic activity to $\mathrm{k}=7$

311 and $\mathrm{k}=4$, respectively. The $\mathrm{k}$ parameter did not need to be set for NAO, SST, or fishing

312 catch because these terms had more unique covariate combinations than the specified

313 maximum degrees of freedom. To avoid fitting overly complex models, the maximum basis

314 size for the smooth terms were limited to these values. Finally, we plotted the residuals by

315 covariate (Supplemental information; GAM model checking) to confirm the goodness of our

316 model fit. These plots showed low variation in the covariate residuals suggesting that the

317 model is a good fit (Fig. S11).

318 We removed 'rare' and 'unknown' records from the final model to account for possible

319 misidentifications in the stranding record. These records were also removed because of the

320 effect one or two records could have on skewing the species smooth. We also ran a GAM

321 with all 'rare' and 'unknown' records included (2,664 records) to investigate the effect of

322 these additional strandings.

323

324

325

326

327

328

329

330 
332 There are many different ways to subdivide the dataset, and many possible sources of error.

333 Therefore, we ran a series of additional analyses on subsets of the data, or different

334 arrangements of the data, to identify any obvious issues. These are described briefly below;

335 for more details see the supplementary information.

336

337 Species identification models

338 We ran the model with all stranding records at genus-level to account for possible

339 misidentification at the species-level, particularly in the historical data. Because species

340 identifications by dedicated strandings networks are likely to be more reliable than those in

341 the historic data, we also ran a model using CSIP and IWDG stranding records only (1990 -

342 2015).

343

\section{Species specific models}

$34547 \%$ of the dataset were harbor porpoise (Phocoena phocoena) records, as these small

346 cetaceans are widespread and abundant in UK and Irish waters (Fig. S4). To ensure that our

347 results were not merely reflecting a signal in the harbor porpoise data we repeated our

348 analyses after removing this species from the dataset, and then for the harbor porpoise data

349 separately. For completeness we also fitted models for all other species with over 100

350 stranding records in the dataset (we excluded five species with fewer than 100 strandings

351 records; sei whale (Balaenoptera borealis), blue whale (Balaenoptera musculus), pygmy

352 sperm whale (Kogia breviceps), humpback whale (Megaptera novaeangliae), and True's

353 beaked whale (Mesoplodon mirus), because they had insufficient data to fit the models.

355 Ship strike models

356 To investigate ship strike effects on strandings we ran a model that included a proxy for

357 shipping traffic around the UK. These data were only available from 1950-2015; therefore, 
358 the other predictors and the response were constrained accordingly, and shipping was not

359 included in the full model. Note that we use shipping traffic as a proxy for ship strikes

360 because direct ship strike data was not available historically, and even those data available 361 mainly focus on mysticetes or are geographically restricted.

362

363 Stranding events models

364 In the main model the response is all individual stranding records, with each and every

365 cetacean in a mass stranding recorded by species, location, and date. Cetaceans that mass 366 strand are generally pelagic odontocetes (Jepson et al. 2013), and we felt it was important to 367 assess the effects of correlates on these mass strandings. We therefore also fitted a model 368 with the number of stranding events as the response (with a single mass stranding event 369 recorded as a ' 1 ' for all individuals of the same species at that location and date) to 370 investigate whether the correlates had a different effect on single and mass strandings, and 371 to see whether our results were reflecting a signal of multiple mass strandings of pelagic 372 odontocetes.

373

374 Suborder models

375 The cetaceans were split by suborder (i.e., Mysticeti or Odontoceti) to investigate whether 376 the predictors affected the numbers of strandings differently in each suborder. The two 377 suborders are generally different ecologically (e.g., diet specialization and larger body size in 378 the mysticetes), and it has been suggested that only some genera (e.g., Delphinus,

379 Grampus, and Ziphius; Kirschvink et al. 1986), of which all are odontocetes, use 380 geomagnetic features to navigate, with Balaenoptera (a mysticete), to a lesser extent 381 (Kirschvink et al. 1986). We therefore investigate the differences in this and the other 382 correlates of strandings for the two suborders.

383 
Habitat models

387 We ran a model with a smooth of habitat (i.e., oceanic, coastal, or both) (Table S2) rather 388 than a species smooth because some of the predictors e.g., storms, may have had more of 389 an effect on species in certain habitats. For example, shallow water species, such as 390 porpoises, may be more likely to strand due to severe weather as they are less able to escape from storm impacts (Lawler et al. 2007, Schumann et al. 2013). Species habitat data 392 were from Reid et al. (2003).

393

\section{Regional models}

395 Finally, we ran two regional models for strandings from; 1) the south west coast of the UK 39 where cetacean stranding records and human population have increased, and 2) the north west cost of the UK where cetacean stranding records have increased, but human population has decreased. These models were run to assess the possible effects that using one standard UK human population size may have had in the original model and to see if

400 correlates of strandings were different in different regions of the UK and Ireland. The same 401 predictors were used in these models but were constrained to 1991-2015 as county-level 402 human population data are only available for this time period.

403 All data required to reproduce our analyses are available from the NHM Data Portal 404 (data.nhm.ac.uk, Coombs et al. 2018). We performed all data cleaning, data exploration, 405 plotting and analyses in R version 3.4.0 (R Core Team, 2017). A fully reproducible workflow 406 is available on GitHub (https://github.com/EllenJCoombs/cetacean-strandings-project) and 407 Coombs et al. (2019). 


\section{Results}

\section{Data exploration}

\section{Temporal and spatial patterns in the strandings data}

414 A total of 17,491 strandings comprising 21 species were recorded. The dataset contains 786

415 mysticete records from five species, and 16,705 odontocete records from 16 species.

416 Temporal and spatial patterns in strandings varied across and within species (Fig. 2, 3).

\section{$418<$ Figure 2>}

$419<$ Figure 3>

420

421 Some species e.g., blue whales and false killer whales (Pseudorca crassidens), stranded in

422 the earlier parts of the time series but then disappear from the strandings record (Fig. 3).

423 Conversely, some species appear for the first time in the latter half of the century. For 424 example, the first humpback whale stranding record was in 1982 and the first pygmy sperm 425 whale stranding was recorded in 1966 (Fig. 2, 3). Species such as northern bottlenose 426 whales (Hyperoodon ampullatus) and Cuvier's beaked whales (Ziphius cavirostris) have 427 stranded consistently throughout the century, with an increase in records towards the 428 present day.

429 Overall, cetacean strandings records have increased over the past century, with a rapid rise 430 from the late 1980 s to the present (Fig. 4). There were several prominent spikes in stranding 431 numbers before the 1990s (Fig. 4) caused by mass strandings. In 1927, there was a mass 432 stranding of 150 false killer whales, with further mass strandings of this species in 1934 and 433 1935, the largest being 41 individuals. In 1950 there were two long-finned pilot whale 
434 (Globicephala melas) mass strandings (totaling 245 individuals; Fig. 2, 4), with further mass

435 strandings of this species in 1983. All of these mass strandings occurred in Scotland, which 436 accounts for the high numbers in that region from 1926-1950 (Fig. 5).

437 The most frequently stranded species were harbor porpoise (Phocoena phocoena; $n=$ 4388,$265 ; 47 \%$ of all stranding records), short-beaked common dolphin (Delphinus delphis; $n=$ 4393,$110 ; 18 \%$ of all stranding records) and long-finned pilot whale (Globicephala melas; $n=$ 4401,$606 ; 9 \%$ of all stranding records) (Fig. 2, 3). Mysticete strandings were much less frequent 441 (Fig. 4) and accounted for around 4\% of total strandings records. Mysticete strandings 442 showed an overall decline throughout the century until the 1980s. Generally stranding 443 records of all odontocetes increased throughout the 1990s to the present. The exceptions 444 were false killer whale, as previously mentioned, and killer whale (Orcinus orca) that 445 stranded intermittently in low numbers, with one mass stranding event $(n=11)$ in 1994 in 446 Scotland. 1990 was the first year that mysticete stranding records reached double figures. 447 There was an increase in mysticete strandings after 1987 and throughout the 1990 s to the 448 present. Minke whales (Balaenoptera acutorostrata) accounted for $79 \%$ of all mysticete 449 strandings and also accounted for the majority of the post-1990 rise in mysticete strandings.

450 Mysticete records remained low throughout the 1950s and 60s (Fig. 4). There was a slight 451 decline in the number of odontocete stranding records during the early period of WWII, but 452 there are other years throughout the time period that reported lower numbers of odontocete 453 strandings. The CSIP and IWDG programs began in 1990, after which there was an 454 increase in stranding records for both mysticetes and odontocetes (Fig. 3, 4).

$<$ Figure 4> 
458 Most strandings were of odontocetes, therefore the plot for odontocetes and all species

459 combined show a similar pattern (Fig. 4). Most strandings occurred around the south coast 460 of England and the west coasts of Ireland and Scotland (Fig. 5, S6). This pattern was 461 particularly evident in common dolphin and harbor porpoise strandings (Fig. S4, S5).

462 Stranding hotspots in southern and southwest England were first documented from 19264631950 (Fig. 5). Over the next $25 \mathrm{yr}(1951-1975)$ there was an increase in stranding records 464 around northern England. Over the next few decades (1976-2000) stranding density 465 increased along the northeast and north of Scotland (Fig. 5). From the 1990s, stranding 466 records can be observed around most of the coastline concomitant with the advent of the 467 modern stranding programs. Mysticete strandings increased around southwest England, 468 southwest and western Ireland and western Scotland in the last few decades (2001-2015; 469 Fig. 5). East Anglia, Wales and eastern Ireland have fewer records for mysticete strandings 470 compared to other parts of the UK and Ireland (Fig. 5).

\section{Correlates of strandings through time}

473 We found significant effects for NAO, SST, and fish catch $(P<0.05, P<0.001, P=0.02$, 474 respectively) suggesting the smooth of these variables were significantly different from "no 475 effect" (Table 2). However, the estimated degrees of freedom (EDF) were very low (i.e., less 476 than, or not much greater than 1) indicating that the number of individuals that strand was 477 not strongly influenced by any of our predictor variables apart from year of stranding (Table

478 2, Fig. 6). The factor smooth term s(Year, Species) has an estimated degrees of freedom 479 (EDF) of 103 (Table 2; deviance explained $=84.5 \%, n=2,163$ ). The results of the GAMs 480 were qualitatively similar when we included all 'rare' and 'unknown' records, except fishing 481 catch had an EDF a little higher than 1 (Table S4, S15, Fig. S15). 
$485<$ Figure 6>

486

487 Sensitivity analyses

488 We found significant $P$-values for some variables in our sensitivity analyses (see below for 489 details) suggesting the smooth of these variables were significantly different from "no effect". 490 However, the EDFs for all variables (with a few exceptions; see below) were low, indicating that 491 across all sensitivity analyses the number of individuals that strand was not strongly 492 influenced by any of our predictor variables, except year of stranding, i.e., our results 493 were qualitatively identical to those for the full model described above. This was true 494 across all sensitivity analyses (Tables S4, S5, S7-S12, S15 and Fig. S15, S16, S18S23); therefore, we only report the differences below. All results are compiled in Table $496 \mathrm{~S} 15$.

497

498 Species identification models

499 In the genus-level models we found significant effects for SST, NAO index, and fishing catch $500(P<0.001, P=0.01, P=0.01$, respectively) (Table S5, Fig. S16). For the CSIP and IWDG 501 (1990 - 2015) data we found significant $P$-values for storms, NAO, fishing catch, and shipping 502 traffic (Table 3, Fig. S17).

503

504 Species specific models

505 When we removed harbor porpoises from the dataset we found significant effects for SST, $506 \mathrm{NAO}$, and fishing catch $(P<0.001, P=0.001, P=0.07$, respectively) (Table S7, Fig. S18) and 507 showed that the original model was not merely reflecting a signal in the harbor porpoise data. When 508 we modelled harbor porpoise only, we found a significant $P$-value for SST $(P<0.01)$ but no

509 influence of any of the other predictor variables. When modelling each species 510 separately, we found no influence of any of the predictor variables (Table 4). 
Ship strike models

513 We found significant $P$-values for all of the variables; storms $(P<0.005)$, geomagnetic k-index $(P<$

$5140.01)$, SST $(P<0.01)$, NAO $(P<0.01)$, fishing catch $(P<0.001)$, and shipping traffic $(P<0.001)$

515 (Table S9, Fig. S20), however, all variables (except fishing catch) had low EDFs (Table S9). The

516 EDF for fishing catch was 5.57, but the relationship was not particularly "wiggly" meaning we can

517 also interpret this as having little effect on the number of stranded individuals (Wood, 2017).

518

519 Stranding events models

520 Our model with the number of stranding events as the response (with a single mass

521 stranding event recorded as a ' 1 ') had a significant $P$-value for maximum SST, NAO and fishing $522 \operatorname{catch}(P=0.005, P<0.001, P=0.04$, respectively) (Table S10, Fig. S21) but EDFs were low.

523 The correlates did not have a different effect on single and mass strandings. Further, our

524 results were not merely reflecting a signal of multiple mass strandings of pelagic

525 odontocetes.

526

527 Suborder models

528 We found a significant effect for maximum SST, and fishing catch $(P<0.005, P<0.001$,

529 respectively) (Table S11, Fig. S22) but otherwise the models for odontocetes and mysticetes

530 were qualitatively similar to those for the full dataset.

531

532 Habitatmodels

533 We found significant effects for maximum SST, and fishing catch $(P=0.001, P<0.001$,

534 respectively) but overall the results were the same as in the models without a habitat smooth

535 (Table S12, Fig. S23).

536

537 Regional models

538 The two regional models had different EDFs, with higher EDFs found in the southwest (region 1)

539 model (Table 3). We found significant $P$-values for all of the variables except for maximum k-index 
540 and maximum SST in both models (Table S13, S14). The region 1 model had an EDF of 6.62 for

541 NAO but the relationship was not particularly "wiggly". We therefore interpret this as having little effect

542 on the number of stranded individuals (Wood, 2017). The EDFs for the other variables were still too

543 low to be fully conclusive (Table 3, Fig. S24, S25).

544

$545<$ Table 3>

546

$547<$ Table 4>

548

549

550

551

552

553

554

555

556

557

558

559

560

561

562

563

564

565

566 


\section{Discussion}

568 We looked at 17,491 UK and Irish cetacean stranding records from 1913-2015 from the

569 Natural History Museum (NHM), the Cetacean Stranding Investigation Programme (CSIP),

570 and the Irish Whale and Dolphin Group (IWDG). We found that stranding numbers

571 increased throughout the century, with hotspots along the southern and western coast of the

572 UK and Ireland. We investigated several potential environmental and anthropogenic

573 predictors: storms, geomagnetic activity, North Atlantic Oscillations, sea-surface

574 temperature, and fishing catch. Except for year of stranding, we found no significant

575 correlation between the numbers of cetaceans stranding each year and these potential

576 predictors.

577

578 Temporal and spatial patterns in the strandings data

579 We found that temporal and spatial variation in cetacean strandings has occurred over the 580 last $100 \mathrm{yr}$ (from 1913-2015) on the shores of the UK and Ireland. Generally, cetacean

581 strandings have increased throughout the century.

582 A reduction in mysticete strandings in the 1950 s is likely to be related to a substantial

583 increase in post-WWII commercial whaling that affected North Atlantic stocks (Braham,

584 1984, Amundsen et al. 1995), reducing the number of individuals available to strand.

585 Mysticete stranding numbers increase after 1987, the year after the International Whaling

586 Commission moratorium on whaling came into effect.

587 Stranding events along the north and west coasts of Britain, south and west coasts of 588 Ireland (McGovern et al. 2016), and around the English Channel, Irish Sea, and Sea of the 589 Hebrides may in part be due to the passive transport of carcasses by the North Atlantic drift 590 (MacLeod et al. 2004). Further, these areas support a higher abundance and diversity of 591 cetaceans, particularly the deep, prey rich waters off the west coasts and continental shelf 
592 (Evans, 1980, Wall et al. 2009, Hammond et al. 2013). Many cetaceans including fin and

593 sperm whales migrate along the west coasts of Ireland and Scotland (Evans, 1980) and are

594 therefore more likely to strand in these regions.

595

596 Studies have highlighted the impacts of bycatch and entanglement as a cause of strandings

597 (Leeney et al. 2008, Parsons et al. 2010, Deaville and Jepson 2011, Prado et al. 2016).

598 Strandings of harbor porpoise and common dolphin were particularly frequent around

599 Cornwall and the southwest coast of England (Leeney et al. 2008, Deaville et al. 2015) and

600 the Isles of Scilly (Sabin et al. 2005). This spatial pattern has been attributed to

601 entanglement in bycatch and intense fishing pressures off the southwest coast, one of the

602 most heavily fished regions of the UK (Leeney et al. 2008, Deaville et al. 2015). Incidences

603 of bycatch and entanglement in fishing gear for smaller cetacean species are generally

604 higher in these regions (Leeney et al. 2008, Deaville and Jepson, 2011, Deaville et al. 2015).

605 Despite an increase in bycatch monitoring and recording effort through initiatives such as the

606 Agreement on the Conservation of Small Cetaceans of the Baltic, North East Atlantic, Irish,

607 and North Seas (ASCOBANS), monitoring of cetacean bycatch in the majority of fisheries

608 and areas is still insufficient (Read et al. 2017). Entanglement in fishing gear also affects

609 larger species and there has been a documented rise in the number of humpback whales

610 caught in static creel lines in Scottish waters (Ryan et al. 2016). Entanglement was the

611 cause of fatality in half of all baleen whales examined at necropsy in Scotland (Northridge et

612 al. 2010), which may help explain high mysticete stranding rates in this region or reflect

613 higher densities of these species in this region. It is also important to note that the proximity

614 of the Atlantic shelf-edge to the Scottish islands, coupled with the influence of the Gulf

615 Stream, make this a particularly rich area for migrating and feeding mysticetes (Evans, 1980,

616 Pollock et al. 2000). 


\section{Correlates of strandings through time}

619 To further investigate spatial and temporal variation, we examined several possible

620 correlates of strandings: storm events, geomagnetic fluctuations, North Atlantic Oscillation

621 (NAO), maximum sea surface temperature (SST), and fishing catch data. However, none of

622 these potential predictors explained the variation in cetacean strandings once we accounted

623 for time. We suggest that this is because the scale of change in the variables is too coarse

624 to detect any potential correlations. Due to the availability of human population data (used as

625 a proxy of sampling effort in our models) we were constrained to examining correlates at

626 yearly intervals. Similar results and criticisms arose from the CSIP and IWDG (1990-2015)

627 data only model, despite this model suffering less from the biases inherent in historical data.

628 Further, the genus-level model and the model with 'rare' and 'unknown' records showed

629 qualitatively similar results most likely due to the coarse, yearly constraints of the models.

630 Below we discuss each correlate in turn.

\section{Storms}

633 We found no significant indication of storms as a correlate for strandings records. Storm

634 events have been reported to have a greater effect on smaller, shallow water species

635 (Lawler et al. 2007, Schumann et al. 2013). However, we found no such effect in any of our

63616 species-specific models, including our harbor porpoise only model, nor in our suborder

637 model despite odontocetes generally having a smaller body size. Further, we found no effect

638 of storms on strandings in our habitat model, despite storms potentially affecting shallow,

639 coastal water species to a greater extent (Lawler et al. 2007). We suggest that these effects

640 may be population, location, or season-specific. Further, carcasses of offshore species may

641 be blown onshore during storm events making species-specific impacts harder to identify;

642 consistent data on carcass condition would be required to analyze this. Stormy weather can

643 increase the chances of mass stranding events in some species, sometimes with multiple 
644 species stranding together (Bogomolni et al. 2010, Schumann et al. 2013), however, we

645 found no effect of storms when we included mass strandings as multiple events (i.e., each

646 species in that location, on that date is a single record). Again, it is likely that the scale of

647 change in our variables is too coarse to model these effects.

648

649 Geomagnetic fluctuations

650 We found no significant indication of geomagnetic fluctuations as a correlate for strandings.

651 Geomagnetic fluctuations may increase the likelihood of stranding in some species, e.g., 652 sperm whales (Smeenk, 1997, Pierce et al. 2007, Vanselow et al. 2017). Only some genera

653 (e.g., Delphinus, Grampus, and Ziphius; Kirschvink et al. 1986) likely use geomagnetic

654 features to navigate, with others to a lesser extent (e.g., Balaenoptera; Kirschvink et al. 655 1986), however, this was not detected in our species-specific models, nor in our suborder 656 model. It should be noted that many of these studies focus on one species in one ocean 657 basin e.g., the effect of geomagnetic activity on sperm whales stranding in the North Sea 658 (Vanselow et al. 2017) and that these regional and species-specific definitions were not 659 investigated in our macroecological study. We did not find a correlation between 660 geomagnetic fluctuations and strandings in our regional models, perhaps because these 661 effects are population, or season-specific.

662

663 North Atlantic Oscillation (NAO)

664 In contrast to other studies (Pierce et al. 2007, Truchon et al. 2013), we found only a slight 665 effect of NAO on the number of stranding events in our main model. However, this was so 666 small that it was inconclusive. Previously, positive NAO indices have been positively 667 correlated with high stranding frequencies for seasonal migratory cetaceans (such as minke 668 whales) in the Atlantic (Truchon et al. 2013). Further, incidences of sperm whale strandings 
669 in the North Sea are higher during warm periods (associated with the NAO and higher SST),

670 a likely reflection on changes in distribution of their prey (Robinson et al. 2005, Pierce et al.

671 2007). Again, this may be because many of these previous studies focus on one species, in

672 a specific geographical region (e.g., the North Sea only (Smeenk, 1997, Pierce et al. 2007,

673 Vanselow et al. 2017), and show regional, and seasonal definitions that are not detected in

674 our wider macroecological study.

675

676 Sea surface temperature (SST)

677 We found only a slight correlation between SST and stranding records in our main model.

678 The EDF was so low, that this is not a conclusive correlate of strandings. Studies that have

679 investigated SST and cetacean strandings are species, and region specific. For example, in

680 western Scotland, the relative frequency of strandings of white-beaked dolphins, a colder

681 water species, have declined whilst strandings of common dolphins, a warmer water

682 species, have increased (MacLeod et al. 2005). We found no such species-specific effects.

683 We also found no effects of SST on strandings in our regional models (southwest UK and

684 northwest UK). The effects of an increase in SST may be particularly profound in species

685 that are constrained to shelf-waters and are unable to retreat to deeper, oceanic waters

686 (MacLeod et al. 2009). However, we saw no such effect of SST in our habitat model. Again,

687 it is likely that the scale of change in our variables is too coarse to model these effects, and

688 further, that seasonal definitions are not investigated in our model.

689

690

691

692 
694 We found only a small correlation between stranding events and fishing catch. It is well 695 known that over-fishing can directly impact cetaceans by reducing their prey (Evans, 1990, 696 Weir et al. 2007), which can lead to starvation, or a shift in cetacean distribution as they 697 search for prey elsewhere. Starvation is a common cause of death recorded in stranding 698 reports (Kirkwood et al. 1997, Deaville and Jepson, 2011, Deaville et al. 2015), with many 699 cases ascertaining that no other significant disease processes could explain the animal's 700 poor nutritional status (Jepson, 2005, Deaville and Jepson, 2011). We found a correlation 701 between fishing catch and strandings in the southwest regional model, the habitat model, 702 and the model with all 'rare' and unknown records included, although these correlations are 703 too small to be conclusive. Future studies should investigate the effects of fishing catch at a 704 finer seasonal, and regional scale, and importantly, in conjunction with bycatch data.

\section{Model criticisms}

707 Our models may have failed to fully explain the variation in cetacean strandings because we 708 did not include other possible predictors such as reported bycatch numbers, or sonar use.

709 Other causes of death, and of strandings include infections from bacteria and other 710 pathogens, impacts of legacy chemical contaminants, particularly in top predators such as

711 killer whales and false killer whales which have seen a decline in stranding records, physical 712 trauma from boat strikes, in addition to interspecific aggression, and starvation (Sabin et al. 713 2005, Deaville and Jepson, 2011, Jepson et al. 2016, Law et al. 2012). Other studies have 714 shown that beaked whales and pilot whales are particularly sensitive to sound pollution from 715 ship sonar and military exercises, causing fatal gas bubble lesions from rapid ascents 716 (Jepson et al. 2003, McGeady et al. 2016, Harris et al. 2017). However, responses varied 717 between, and within, individuals and populations (Harris et al. 2017). We were unable to 718 include these variables because data were not available for the full time period of our 
719 stranding dataset at a yearly resolution. In addition, they have been addressed elsewhere

720 through the work of the current UK strandings program (e.g., Deaville and Jepson, 2011,

721 Jepson et al. 2016).

722 Our results may be confounded by the way we performed our analyses. First, we were

723 unable to account, in a satisfactory way, for sampling effort, instead using yearly UK

724 population size as a proxy. This is problematic as it cannot take into account social and

725 attitudinal changes over the 103-year period that are likely to have had a significant impact

726 on reporting effort. In addition, we used a population measure for the whole UK, which

727 shows that apart from the years 1916-1918 (i.e., WWI), the human population rose every

728 year (Supplemental information: Human population data). A total UK population count

729 misrepresents some rural counties that have seen population fluctuations (for example

730 Anglesey, Wales) or declines (for example Argyll and Inverclyde, Scotland; and Donegal,

731 Ireland). Our two regional models, one for the southwest UK where human population has

732 increased over the century, and one for the northwest of Scotland where human population

733 has decreased over the century, were designed to account for this, but we did not find much

734 variation in our results. A better model would incorporate monthly human population data for

735 each county with a coastline, for the period 1913-2015, and therefore represent changing

736 sampling effort in that region over the century. This would also allow us to model the other

737 variables at monthly intervals. We could not incorporate these data because county-level

738 population data dating back to 1913 is only available decadally in UK and Irish Census data,

739 and county (and country) boundaries have changed in this time. Further, fluctuations in

740 stranding records may be attributable to uneven observer effort caused by specific events,

741 for example reduced effort during and after both world wars (Klinowska 1985).

742 We also highlight that the spatio-temporal difference between the death of the animal and its

743 discovery may affect stranding records, but that this is too variable to model. This includes

744 factors such as initial location of the animal at the time of death, buoyancy of the 
745 carcass/species, and proximity of the carcass to strong currents, all of which determine

746 where and if the animal washes up.

747

\section{Sampling effort}

749 It is most likely that the increase in stranding records throughout the 1980 s to the present

750 was due to an increase in observer effort (Leeney et al. 2008, Deaville and Jepson, 2011,

751 Pyenson, 2011) and dedicated recording effort from the CSIP and the IWDG from 1990

752 onwards. It may also be the result of an increase in interest and reporting (O'Connell and

753 Berrow, 2007), and knowledge of the public (Norman et al. 2004, Leeney et al. 2008). An

754 increase in stranding records from the late 1980s onwards was also reported from southeast

755 Australia (Evans et al. 2005), the northwest Pacific in the USA (Norman et al. 2004), and

756 from the Hawaiian Islands (Maldini et al. 2005). These increases are also associated with an

757 increase in observer effort, and the formation of formal strandings networks. We see this

758 pattern in the UK and Irish stranding data.

759 Overall, we found numerous potential drivers of cetacean stranding events, but that the

760 causes of strandings often remain undetermined (Dolman et al. 2010). Cetaceans in UK

761 and Irish waters are facing numerous challenges such as reductions in prey stocks,

762 increases in chemical and noise pollution, and bycatch/entanglement (Parsons et al. 2010,

763 Deaville and Jepson, 2011). It is likely that the number of stranded cetaceans will continue to

764 rise as reporting effort and public interest in cetaceans continue to increase, and further, as

765 environmental and anthropogenic pressures on cetaceans persist. We suggest that future

766 studies continue to consider these anthropogenic threats that are likely to affect the numbers

767 of cetaceans that strand.

768 Long-term strandings data provides vital information on past and present cetacean diversity

769 and distribution for common, rare, and inconspicuous species, highlighting the importance of 
770 stranding programs. Such data on cetaceans can provide an indication of wider ecosystem

771 health (Friedlaender et al. 2006, Roman et al. 2014) making these an important data source

772 to consider when informing conservation decisions.

773

\section{Acknowledgements}

775 We thank David L Miller for his advice on GAMs, Sarah Reay and Susan Macmillan from the

776 British Geological Survey, Paul Kiernan of the IWDG, Chris Brierley at University College

777 London, staff at the Met Office, the Office of National Statistics, National Records of

778 Scotland, the Northern Ireland Statistics and Research Agency, and the Plymouth Marine

779 Laboratory. We also acknowledge and thank all the agencies, volunteers and members of

780 public that have collected strandings data in both the UK and Ireland. IWDG receives

781 funding from the Department of Communications, Climate Action and Environment through

782 the IEN and the National Parks and Wildlife Service of the Department of Arts, Heritage,

783 Regional, Rural and Gaeltacht Affairs. The CSIP is co-funded by the Department for

784 Environment, Food and Rural Affairs and Scottish and Welsh Governments. EJC was

785 supported by London Natural Environment Research Council Doctoral Training Partnership

786 (London NERC DTP) training grant NE/L002485/1.

787

788

789

790

791

792

793 
Amundsen, E. S., T, Bjorndal, and J. O. N. M. Conrad. 1995. Open access harvesting of the Northeast Atlantic minke whale. Environmental \& Resource Economics, 6:167-185.

Bejder, L., A. Samuels, H. Whitehead, et al. 2006. Decline in relative abundance of bottlenose dolphins exposed to long-term disturbance. Conservation Biology, 20(6):1791-1798.

800

Bogomolni, A. L., K. R. Pugliares, S. M Sharp, et al. 2010. Mortality trends of stranded 801 marine mammals on Cape Cod and southeastern massachusetts, USA, 2000 to 2006.

802 Diseases of Aquatic Organisms, 88(2):143-155.

803

Braham, H. W. 1984. The status of endangered whales: An overview. Marine Fisheries 804 Review, 46:2-6.

805

Burek, K. A., F.M.D. Gulland, and T. M O'Hara. 2008. Effects of climate change on Arctic 806 marine mammal health. Ecological Applications, 18:S126-S134.

807 Cetacean Stranding Investigation Programme (CSIP). 2019. www.ukstrandings.org

808

Connor, D. W., P.M. Gilliand, N. Golding, and P. Robinson. 2006. UKSeaMap: the mapping

809 of seabed and water column features of UK seas. Retrieved from

810 http://www.jncc.gov.uk/page-3918

Coombs. E. J., R. Deaville, R. C. Sabin, et al. 2018. Dataset: What can cetacean stranding records tell us? A study of UK and Irish cetacean diversity over the past 100 years. Natural History Museum Data Portal (data.nhm.ac.uk). https://doi.org/10.5519/0090038

814 Coombs. E. J., R. Deaville, R. C. Sabin, et al. 2019. GitHub: ellenjcoombs/cetacean-

815

816 stranding-project: release for publication. Zenodo.

https://doi.org/10.5281/zenodo.2613807

817 Deaville, R., and P. D. Jepson, P.D. (compilers). 2011. UK Cetacean Strandings 818 Investigation Programme Final report for the period $1^{\text {st }}$ January $2005-31^{\text {st }}$ December 2010.

820 Deaville, R., P. D. Jepson, M. Perkins, et al. 2015. Cetacean Stranding Investigation 821 Programme Annual Report for the period 1st January - 31st December 2015. 
823 Dolman, S. J., E. Pinn, R. J. Reid, et al. 2010. A note on the unprecedented strandings of 56 deep-diving whales along the UK and Irish coast. Marine Biodiversity Records, 3:e16.

825 Evans, P. G. H. 1980. Cetaceans in British waters. Mammal Review, 10:1-52.

826 Evans, P. G. H. 1990. European cetaceans and seabirds in an oceanographic context. $827 \quad$ Lutra, 33:95-125.

828 Evans, P. G. H., and P.S. Hammond. 2004. Monitoring cetaceans in European waters. 829 Mammal Review, 34:131-156.

830 Evans, K., R. Thresher, R. M. Warneke, et al. 2005. Periodic variability in cetacean strandings: links to large-scale climate events. Biology Letters, 1:147-150.

832 Friedlaender, A. S., P. N. Halpin, S.S. Qian, et al. 2006. Whale distribution in relation to prey 833 abundance and oceanographic processes in shelf waters of the Western Antarctic Peninsula. Marine Ecology Progress Series, 317:297-310.

835

Guisan, A., T. C. Edwards, and T. Hastie. 2002. Generalized linear and generalized additive 836 models in studies of species distributions: setting the scene. Ecological Modelling, 157: 89-100.

839

Halpin, P.N., A.J. Read, E. Fujioka, et al. 2009. OBIS-SEAMAP: The world data center for marine mammal, sea bird, and sea turtle distributions. Oceanography, 22:104-115

840 Hammond, P. S., K. MacLeod, P. Berggren, et al. 2013. Cetacean abundance and distribution in European Atlantic shelf waters to inform conservation and management. Biological Conservation, 164:107-122.

843 Harris, C. M., L. Thomas, E.A, Falcone, et al. 2018. Marine mammals and sonar: Dose844 response studies, the risk-disturbance hypothesis and the role of exposure context. 845 Journal of Applied Ecology, 55(1):396-404.

846 Hurrell, J. W. 1995. Decadal Trends in the North Atlantic Oscillation: Regional Temperatures 847 and Precipitation. Science, 269:676-679.

848 Irish Whale and Dolphin Group (IWDG). 2019. http://www.iwdg.ie/ 
Jepson, P. D., M. Arbelo, R. Deaville, et al. 2003. Gas-bubble lesions in stranded cetaceans. Nature, 425(6958):575-576.

Jepson, P. D. 2005. Cetacean Strandings Investigation and Co-ordination in the UK. Final report to the Department for Environment, Food and Rural Affairs.

Jepson, P. D, R. Deaville, K. Acevedo-Whitehouse, et al. 2013.What Caused the UK's Largest Common Dolphin (Delphinus delphis) Mass Stranding Event? PLoS ONE 8(4): e60953.

Jepson, P. D., R. Deaville, J. L. Barber, et al. 2016. PCB pollution continues to impact populations of orcas and other dolphins in European waters. Scientific Reports, 6:18573.

860

861

862

863

864

865

866

867

868

869

870

871

872

873

874

875

876

877

Kirkwood, J. K., P. M Bennett, P. D. Jepson, T. Kuiken, V. R. Simpson, and J. R. Baker. 1997. Entanglement in fishing gear and other causes of death in cetaceans stranded on the coasts of England and Wales. The Veterinary Record, 141(4):94.

Kirschvink, J. L., A. E. Dizon and J. A. Westphal. 1986. Evidence from Strandings for Geomagnetic Sensitivity in Cetaceans. Journal of Experimental Biology, 120(1):1-24.

Klinowska, M. (1985). Cetacean Live Stranding Sites Relate to Geomagnetic Topography. Aquatic Mammals, 1:27-32.

Kremers, D., J. López Marulanda, M. Hausberger, and A. Lemasson. 2014. Behavioural evidence of magnetoreception in dolphins: detection of experimental magnetic fields. Naturwissenschaften, 101(11):907-911.

Laist, D. W., A. R. Knowlton, J. G. Mead, A. S. Collet, and M. Podesta, M. 2001. Collisions between ships and whales. Marine Mammal Science, 17(1):35-75.

Lamb, H., and K. Frydendahl. 1991. Historic storms of the North Sea, British Isles, and Northwest Europe. International Journal of Climatology (Vol. 12). Cambridge University Press.

Law, R. J., J. Barry, J. L. Barber, et al. 2012. Contaminants in cetaceans from UK waters: Status as assessed within the Cetacean Strandings Investigation Programme from 1990 to 2008. Marine Pollution Bulletin, 64(7):1485-1494. 
Lawler, I. R., G. Parra and M. Noad. 2007.Vulnerability of marine mammals in the Great Barrier Reef to climate change (Chapter 16, Part II: Species and species groups). In Climate Change and the Great Barrier Reef: A Vulnerability Assessment. Townsville: Great Barrier Reef Marine Park Authority. Chapter 16.

Leeney, R. H., R. Amies, A.C. Broderick, M. J. Witt, J. Loveridge, J. Doyle, and B.J. Godley. 2008. Spatio-temporal analysis of cetacean strandings and bycatch in a UK fisheries hotspot. Biodiversity and Conservation, 17(10):2323-2338.

Lloyd, H. B., and G. A. Ross. 2015. Long-term trends in cetacean incidents in New South 886 Wales, Australia. Australian Zoologist, 37(4):492-500.

MacLeod, C. D., G. J. Pierce, and M.B. Santos. 2004.Geographic and temporal variations in 888 strandings of beaked whales (Ziphiidae) on the coasts of the UK and the Republic of Ireland from 1800-2002. Journal of Cetacean Research and Management, 6(1):79-86.

MacLeod, C. D., S. M. Bannon, G. J. Pierce, C. Schweder, J. A. Learmonth, J. S. Herman, 891 and R. J. Reid. 2005. Climate change and the cetacean community of north-west

MacLeod, C .2009. Global climate change, range changes and potential implications for the 894 conservation of marine cetaceans: a review and synthesis. Endangered Species Research, 7(2):125-136

Maldini, D., L. Mazzuca, and S. Atkinson. 2005. Odontocete Stranding Patterns in the Main 897 898

Marra, G., and S. N. Wood. 2011. Practical variable selection for generalized additive 900 models. Computational Statistics and Data Analysis, 55(7):2372-2387.

McGeady, R., B. McMahon, and S. Berrow. 2016. The effects of seismic surveying and 902 environmental variables on deep diving odontocete stranding rates along Ireland's coast. Proceedings of Meetings on Acoustics. stranding records of cetaceans on the Irish coast, 2002-2014. Journal of the Marine Biological Association of the United Kingdom. 
Mignucci-Giannoni, A. A., G. M. Toyos-González, J. Pérez-Padilla, M. A, Rodríguez-López, and J. Overing. 2000. Mass stranding of pygmy killer whales (Feresa attenuata) in the British Virgin Islands. Journal of the Marine Biological Association of the United Kingdom, 80(4):759-760.

Moore. M. J., and J. M. Van Der Hoop. 2012. The Painful Side of Trap and Fixed Net Fisheries: Chronic Entanglement of Large Whales. Journal of Marine Biology, Volume 2012, Article ID 230653.

Morin, P. A., S.C. Baker, R. S. Brewer, A.M. Burdin, M. L. Dalebout, J. P. Dines, and P.R, Wade. 2017. Genetic structure of the beaked whale genus Berardius in the North Pacific, with genetic evidence for a new species. Marine Mammal Science, 33(1):96111.

919

Murphy, S. E., J.S. Herman, G. J, Pierce, E. Rogan, and A.C. Kitchener. 2006. Taxonomic 920 Status and Geographical Cranial Variation of Common Dolphins (Delphinus) In the

Natural History Museum. 2018. Dataset: Historical UK cetacean strandings dataset. Natural 922 History Museum Data Portal (data.nhm.ac.uk). https://doi.org/10.5519/0028204

Norman, S. A., C.E, Bowlby, M.S. Brancato, J. Calambokidis, D. Duffield and P.J. Gearin. 924 925 2004. Cetacean strandings in Oregon and Washington between 1930 and 2002. Journal of Cetacean Research Management, 6(1):87-99.

926

Northridge, S., A. Cargill, A. Coram, L. Mandleberg, S. Calderan, B. Reid and M.H. Wirz. 927 2010. Entanglement of minke whales in Scottish waters; an investigation into 928 occurrence, causes and mitigation. Sea Mammal Research Unit. Final Report to Scottish Government CR/2007/49.

O'Connell, M., and S. Berrow. 2007. Records from the Irish Whale and Dolphin Group for 2006. Source: The Irish Naturalists' Journal, 28(11):459-466. cetaceans: A review of the threats and protection afforded to whales, dolphins, and porpoises in UK waters, part 2. Journal of International Wildlife Law and Policy, 13(2):99-175. 
Pierce, G. J., M. B. Santos, C. Smeenk, A. Saveliev, and A. F. Zuur. 2007. Historical trends in the incidence of strandings of sperm whales (Physeter macrocephalus) on North Sea coasts: An association with positive temperature anomalies. Fisheries Research, 87(23):219-228.

940 941

942

943

944

945

946

947

948

949

950

951

952

953

954

955

956

957

958

959

960

961

962

963

964

Pollock, C. M., R. Mavor, C. R. Weir, A. Reid, R.W. White, M.L. Tasker, A. Webb, and J. B. Reid. 2000. The distribution of seabirds and marine mammals in the Atlantic Frontier, north and west of Scotland. Joint Nature Conservation Committee (JNCC).

Prado, J. H. F., P.H. Mattos, K. G. Silva, and E.R. Secchi. 2016. Long-term seasonal and interannual patterns of marine mammal strandings in subtropical western South Atlantic. PLoS ONE, 11(1).

Pyenson, N. D. 2010. Carcasses on the coastline: measuring the ecological fidelity of the cetacean stranding record in the eastern North Pacific Ocean. Paleobiology, 36(3): 453-480.

Pyenson, N. D. 2011. The high fidelity of the cetacean stranding record: insights into measuring diversity by integrating taphonomy and macroecology. Proceedings: Biological Sciences, 278(1724):3608-3616.

R: A language and environment for statistical computing. R Foundation for Statistical Computing, Vienna, Austria. URL https://www.R-project.org/.

Ramp, C., J. Delarue, P. J, Palsbøll, R. Sears, and P.S. Hammond. 2015. Adapting to a Warmer Ocean Seasonal Shift of Baleen Whale Movements over Three Decades. PLOS ONE, 10(3):e0121374.

Read, F. L., P. G. H. Evans, and S. J. Dolman. 2017. Cetacean Bycatch Monitoring and Mitigation under EC Regulation 812/2004 in the Northeast Atlantic, North Sea and Baltic Sea from 2006 to 2014. Whale and Dolphin Conservation.

Reeves, R. R., B. D. Smith, E. A. Crespo, and G. N. di Sciara. 2003. Dolphins, whales, and porpoises: 2003-2010 conservation action plan for the world's cetaceans. IUCN Species Survival Commission (Vol. 658).

Reid, J.B., P. G. H Evans, and S. P. Northridge. 2003. Atlas of Cetacean distribution in north-west European waters. 
965 Reiss, P. T., and R. Todd Ogden. 2009. Smoothing parameter selection for a class of semiparametric linear models. Journal of the Royal Statistical Society. Series B: Statistical Methodology, 71(2):505-523.

Robinson, R. A., J. A. Learmouth, A. M. Hutson, et al. 2005. Climate change and migratory 969 species. BTO Research Report 414.

Roman, J., J. A. Estes, L. Morissette, et al. 2014. Whales as marine ecosystem engineers. Frontiers in Ecology and the Environment. John Wiley \& Sons, Ltd.

972 Ryan, C., R. Leaper, and P. G. H. Evans. 2016. Entanglement: an emerging threat to humpback whales in Scottish waters. International Whaling Commission.

974 Sabin, R. C., C. J. H. Spurrier, P. D. J, Chimonides, et al. 2005. Cetaceans strandings investigation and co-ordination in the UK for the period 1st January 2000 - 31st December 2004. Consultancy Report to the Department for Environment, Food and Rural Affairs.

978

979

980

981

982

983

984

985

986

987

988

989

990

991

Schumann, N., N. J. Gales, R. G. Harcourt, and J. P. Y. Arnold. n.d. Impacts of climate change on Australian marine mammals. Source: Australian Journal of Zoology, 61(2): $146-159$.

Simmonds, M. P., and J. W. Eliott, W. J. 2009. Climate change and cetaceans: Concerns and recent developments. Journal of the Marine Biological Association of the United Kingdom, 89(1):203-210.

Simmonds, M. P. 2012. Cetaceans and Marine Debris: The Great Unknown. Journal of Marine Biology, 2012:1-8.

Smeenk, C. 1997. Strandings of sperm whales (Physeter macrocephalus) in the North Sea: history and patterns. Bulletin De L'institut Royal Des Sciences Naturelles De Belgique: 15-28.

Truchon, M. H., L. Measures, V. L'Hérault, J. C Brêthes, et al. 2013. Marine Mammal Strandings and Environmental Changes: A 15-Year Study in the St. Lawrence Ecosystem. PLoS ONE, 8(3): e59311. 
992 Vanselow, K., S. Jacobsen, C. Hall and S. Garthe. 2018. Solar storms may trigger sperm 993 whale strandings: Explanation approaches for multiple strandings in the North Sea in 994 2016. International Journal of Astrobiology, 17(4): 336-344.

995 Wall, D., I. O'kelly, P. Whooley and P. Tyndall. 2009. New records of blue whales 996 (Balaenoptera musculus) with evidence of possible feeding behaviour from the 997 continental shelf slopes to the west of Ireland. Marine Biodiversity Records, 2, e128.

998 Weir, C. R., K. A. Stockin and G. J. Pierce. 2007. Spatial and temporal trends in the 999 distribution of harbour porpoises, white-beaked dolphins and minke whales off 1000 Aberdeenshire (UK), north-western North Sea. Journal of the Marine Biological 1001 Association of the United Kingdom, 87(1):327-338.

1002

Wood, S. N. 2011. Fast stable restricted maximum likelihood and marginal likelihood 1003 estimation of semiparametric generalized linear models. Journal of the Royal Statistical

1004 Society: Series B (Statistical Methodology), 73(1):3-36.

1005 Wood, S. N. 2017. Generalized Additive Models: An Introduction with R. CRC Texts in 1006 Statistical Science. Second Edition. 

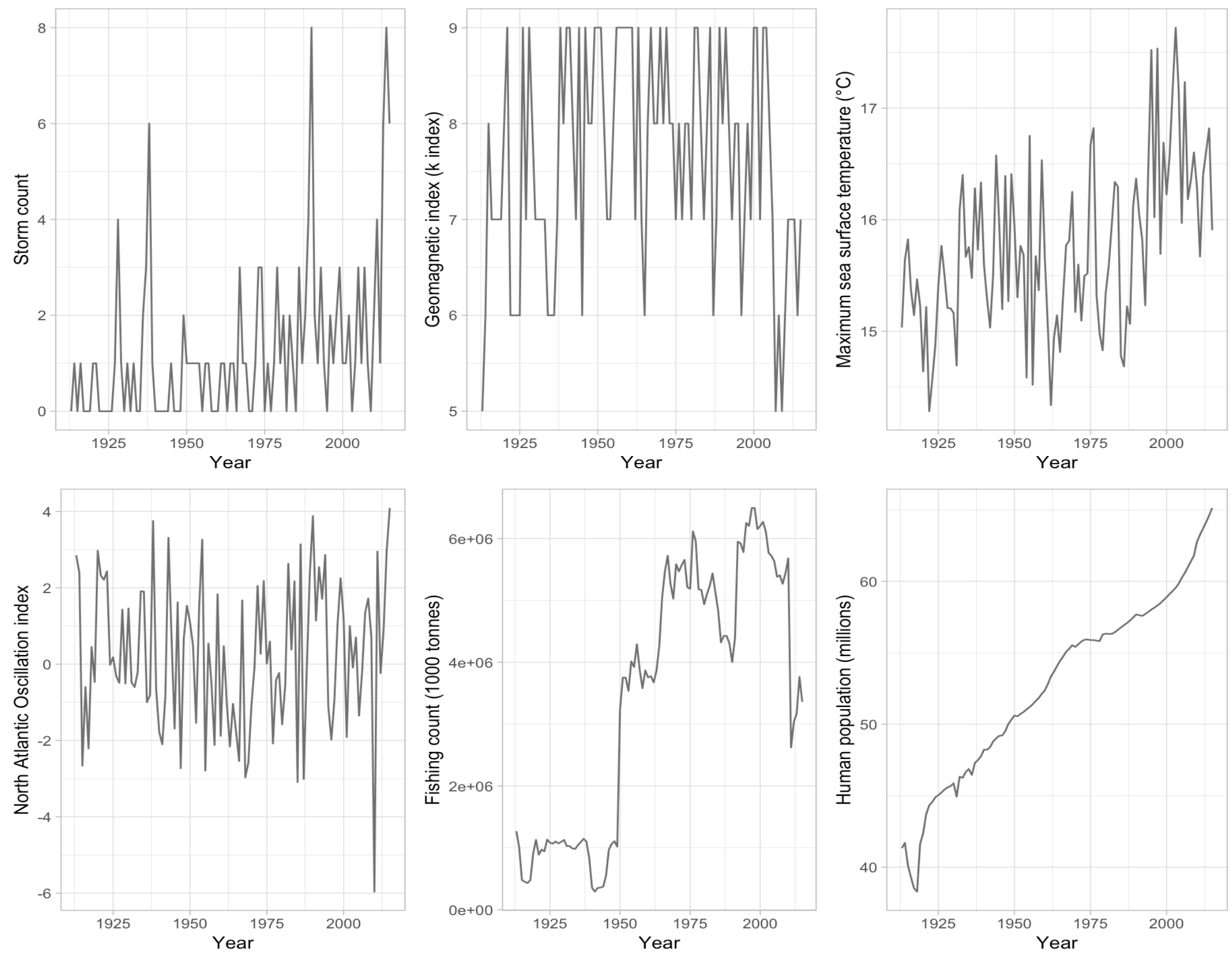


\section{8 <Plot on previous page>}

1009 Figure 1. Predictor variables thought to correlate with cetacean strandings. From top left to

1010 bottom right: Storm count, Geomagnetic index (k-index), maximum sea surface temperature

$1011\left({ }^{\circ} \mathrm{C}\right)$, North Atlantic Oscillation index, Fishing count (1,000 tons), and human population

1012 (millions). All variables show data for the UK and Ireland, apart from Geomagnetic index and

1013 human population which show data for the UK only. All data are shown from $1913-2015$.

1014 Details on how the data were obtained is in Table 1 and the Supplemental Information; Data

1015 collection. Extra details on each of the variables are in the Supplemental information; Data

1016 collection. 

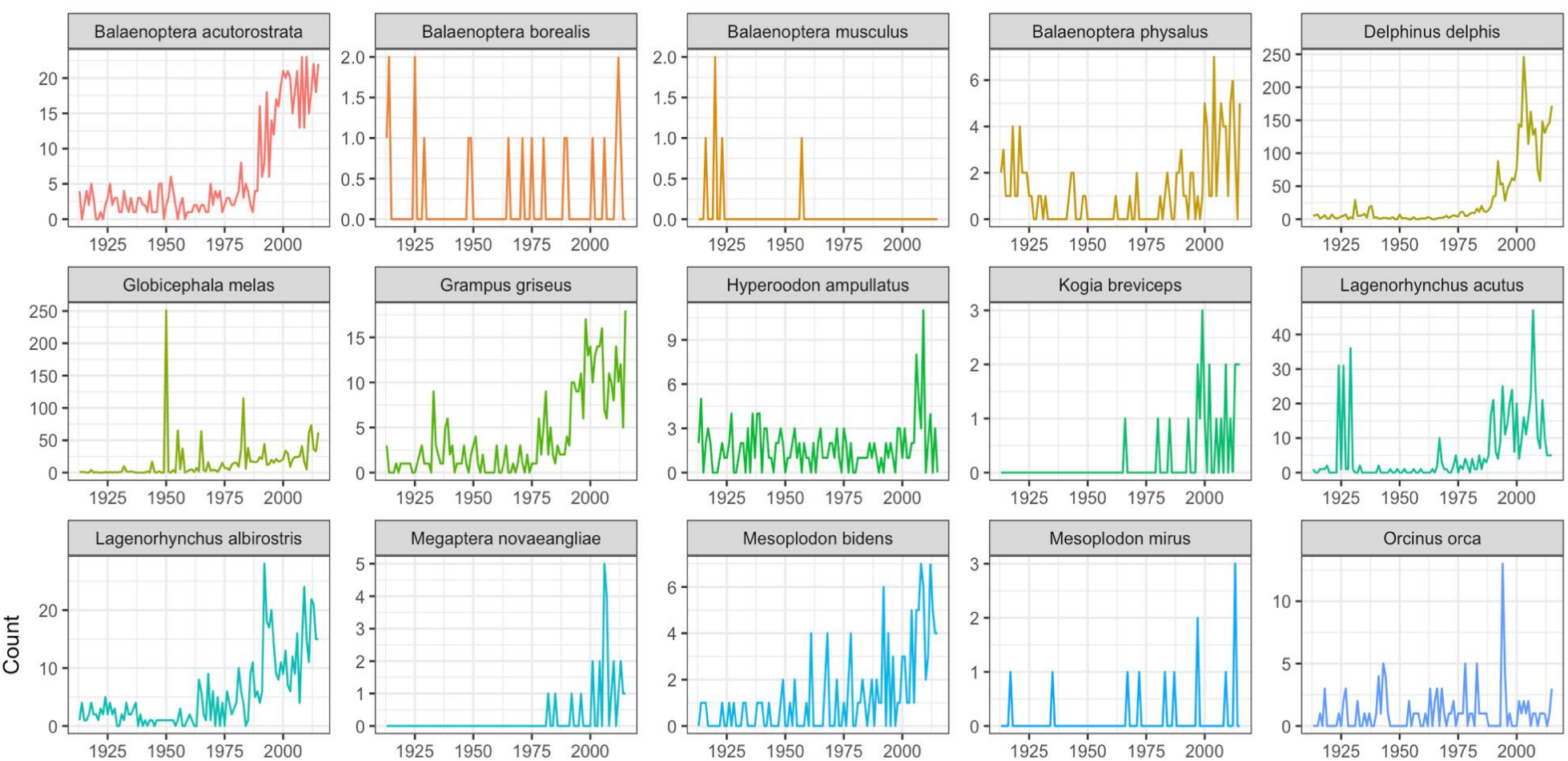

Species

- Balaenoptera acutorostrata - Megaptera novaeangliae

- Balaenoptera borealis _ Mesoplodon bidens

- Balaenoptera musculus - Mesoplodon mirus

- Balaenoptera physalus - Orcinus orca

- Delphinus delphis _ Phocoena phocoena

- Globicephala melas

$\begin{array}{llll}1925 & 1950 & 1975 & 2000\end{array}$

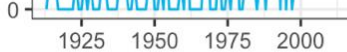

$\begin{array}{llll}1925 & 1950 & 1975 & 2000\end{array}$

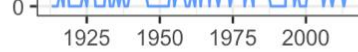

- Grampus griseus

- Physeter macrocephalus
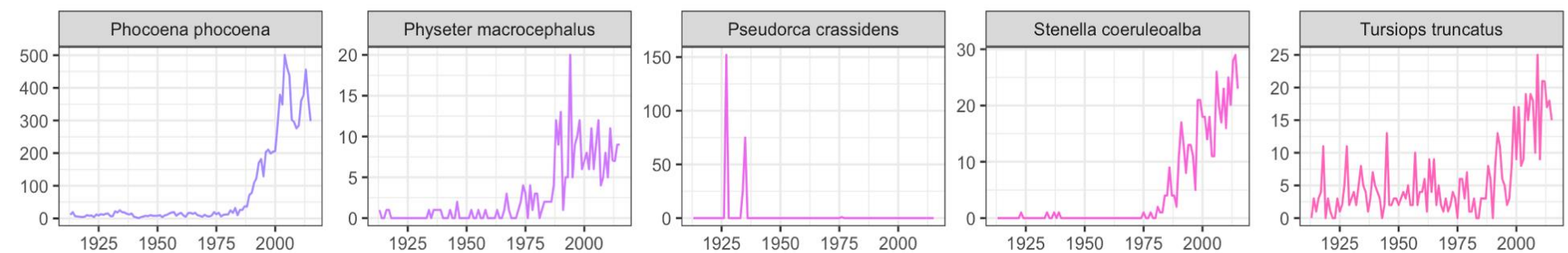

- Hyperoodon ampullatus

- Kogia breviceps

- Pseudorca crassidens

- Lagenorhynchus acutus

- Tursiops truncatus

— Lagenorhynchus albirostris

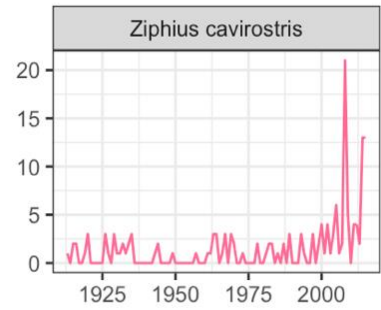


$1018<$ Plot on previous page>

1019 Figure 2. Temporal stranding patterns of each cetacean species stranding in the UK and 1020 Ireland from 1913-2015. The y-axis shows total stranding count per year, the x-axis shows 1021 the year. Note that $y$-axis scales are different for different species. 


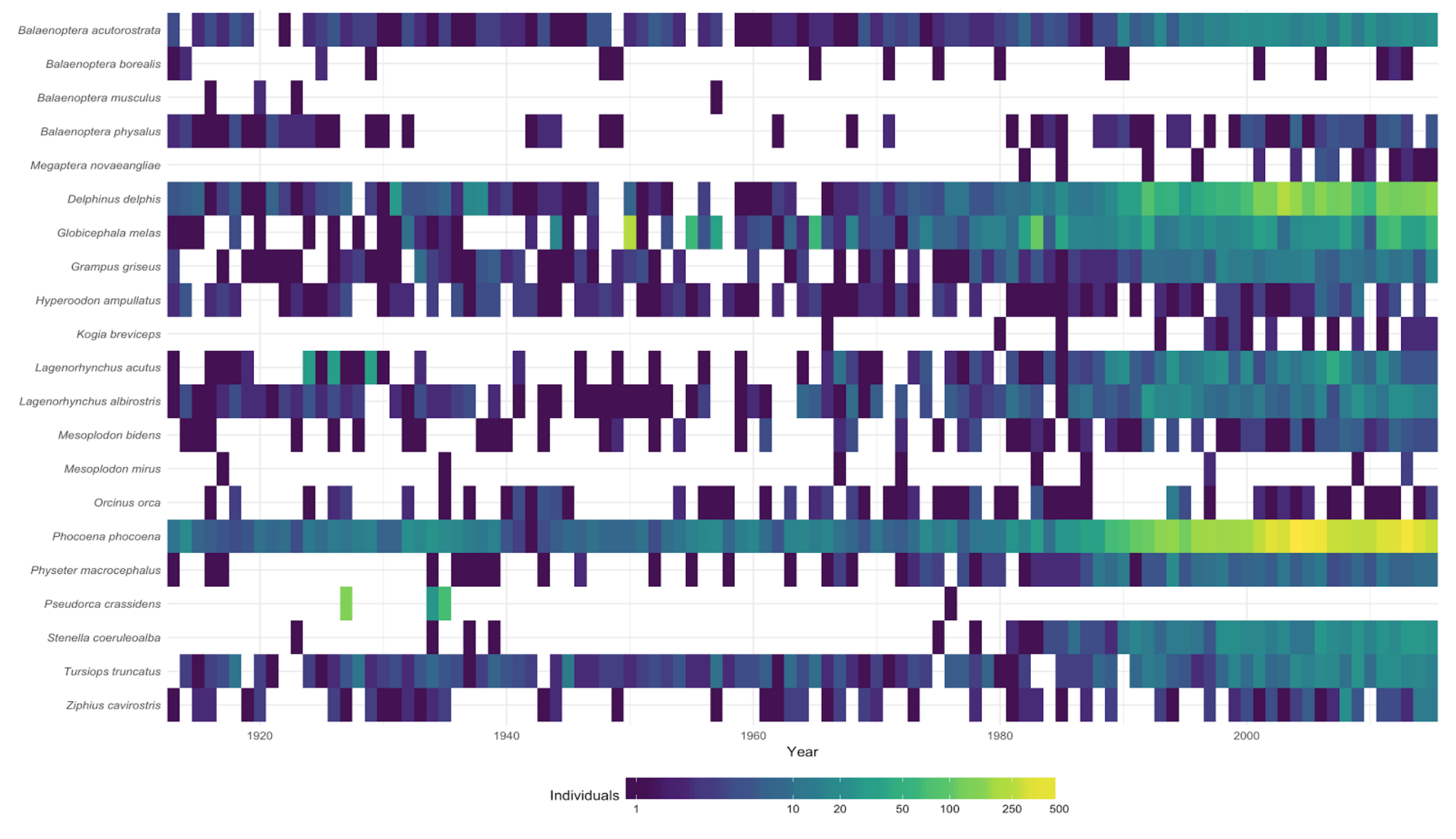


$1024<$ Plot on previous page>

1025 Figure 3. Stranding events of cetacean species in UK and Irish waters from 1913-2015. The $1026 \mathrm{x}$ axis shows the years 1913-2015 with individual tiles representing one year. The y axis 1027 shows the species found in the UK and Irish stranding records. The first five species are 1028 mysticetes (baleen whales), and the rest of the species are odontocetes (toothed whales). 1029 The colored boxes show the number of individuals that stranded each year. Dark blue shows 1030 one to a few individuals, yellow shows more than 200 individuals.

1031 


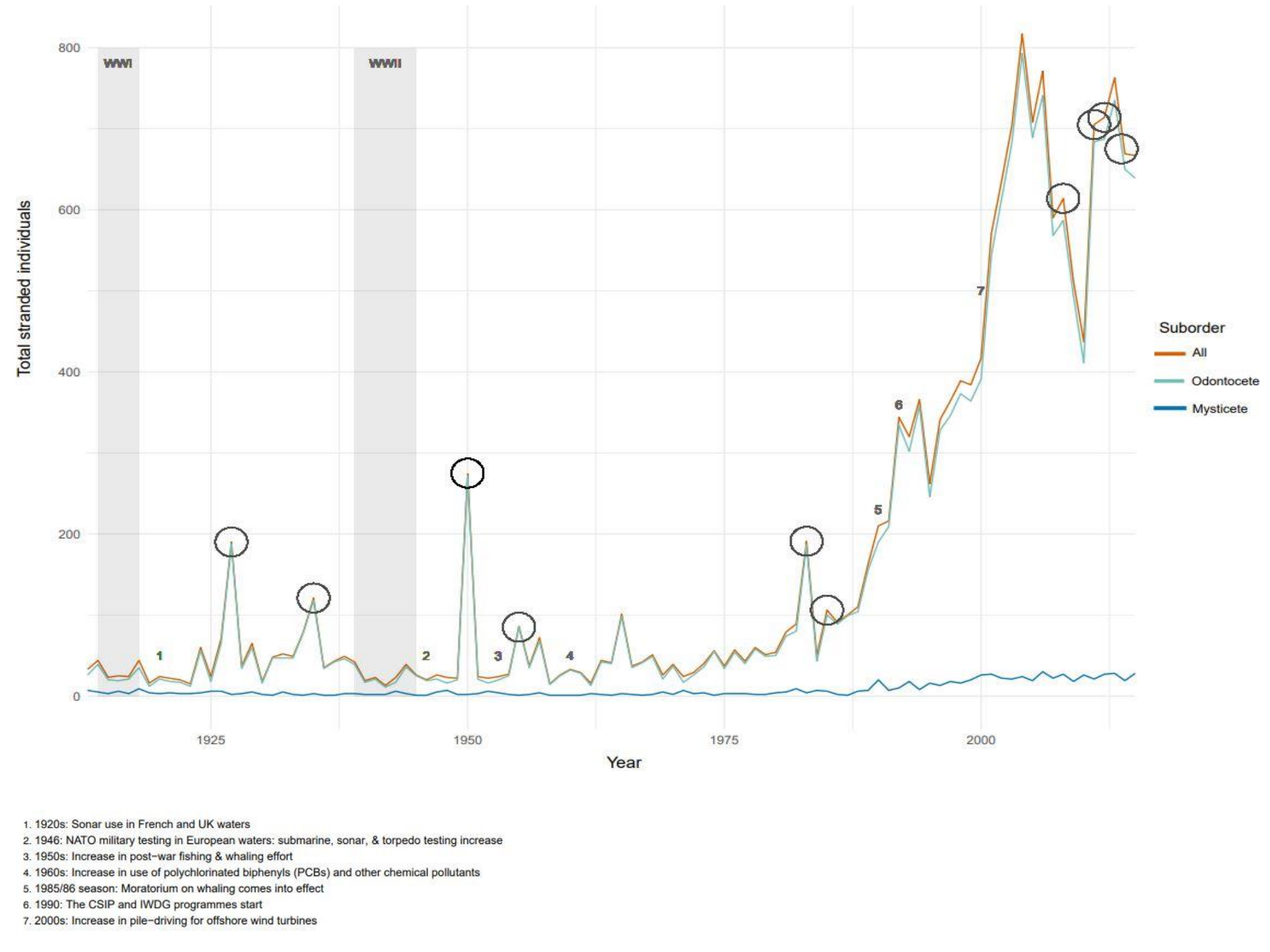


$<$ Plot on previous page $>$

1037 Figure 4. Temporal variation in cetacean strandings records for all species, odontocetes 1038 (toothed whales), and mysticetes (baleen whales) in the waters around the UK and Ireland 1039 from 1913-2015. 1913 is when the NHM started to record cetacean strandings. The plot 1040 shows strandings through time for all species (orange), odontocetes (blue), and mysticetes 1041 (green). The y axis shows total number of individuals that stranded each year. Key 1042 anthropogenic events are labelled with numbers, with the corresponding key below the plot. 1043 Key periods are shaded in light grey. WWI is World War I, WWII is World War II, CSIP is the 1044 Cetacean Stranding Investigation Programme, IWDG is the Irish Whale and Dolphin Group 1045 Cetacean Stranding Scheme. The circles highlight years with mass strandings of $>20$ 1046 individuals. 





$<$ Plot on previous page >

1051 Figure 5. Temporal and spatial variation in cetacean stranding records for all species,

1052 odontocetes (toothed whales), and mysticetes (baleen whales) in the waters around the UK 1053 and Ireland from 1913-2015 at 25-year intervals. Low numbers of strandings are shown as 1054 dark blue, higher numbers of strandings shown in light green, the highest numbers of 1055 strandings are shown in yellow.

1056

1057

1058

1059 Table 1. Predictor variables thought to correlate with cetacean strandings. Units, data type, 1060 and source of raw data are shown. SST is sea surface temperature, NAO is North Atlantic 1061 Oscillation. Human population data are used as an offset in our models. Details on how each 1062 of these variables were sourced and calculated can be found in the Supplemental 1063 information: Data analysis.

1064

1065 <Table on next page>

1066

1067

1068

1069

1070

1071

1072

1073

1074

1075

1076

1077

1078

Variable

Sources 
(units)

$\begin{array}{lll}\text { Storm events } & \text { Storm events over } 47 \text { knots } & \text { Lamb and Frydendahl (1991) } \\ \text { (count/year) } & \text { Met Office, UK }\end{array}$

Multiple sources:

https://github.com/EllenJCoombs/strandings-

project

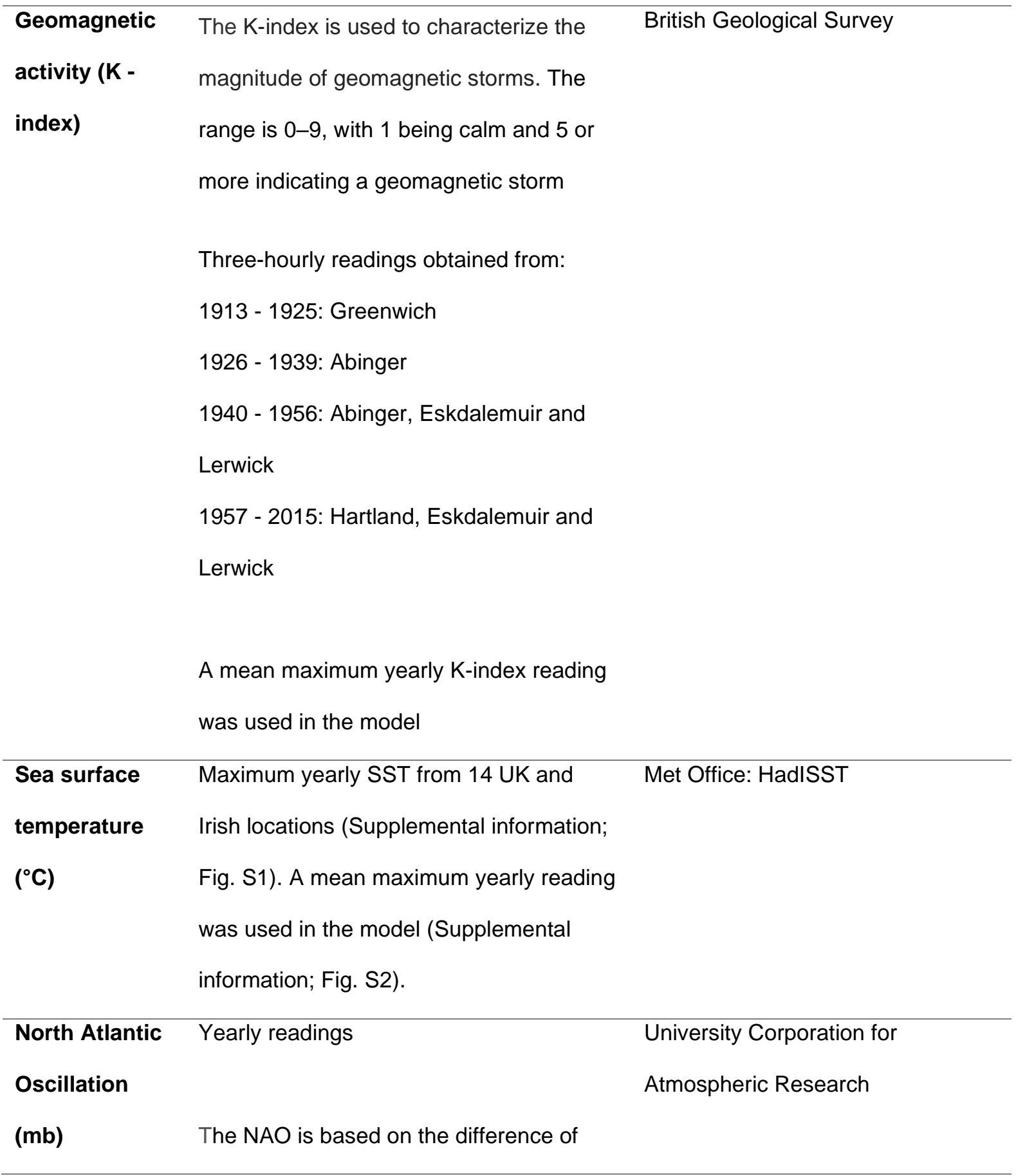




\begin{tabular}{|c|c|c|}
\hline & $\begin{array}{l}\text { normalized sea level pressure (SLP) } \\
\text { between Stykkisholmur/Reykjavik, } \\
\text { Iceland, and Lisbon, Portugal. }\end{array}$ & \\
\hline $\begin{array}{l}\text { Yearly fishing } \\
\text { catch (1000 } \\
\text { tonnes) }\end{array}$ & $\begin{array}{l}\text { Total yearly catch (1000 tonnes) data of } \\
58 \text { species in UK and Ireland. Combined } \\
\text { datasets for England and Wales, } \\
\text { Scotland, Northern Ireland, and Ireland to } \\
\text { get a yearly total. }\end{array}$ & $\begin{array}{l}\text { International Council for the } \\
\text { Exploration of the Sea (ICES) }\end{array}$ \\
\hline $\begin{array}{l}\text { UK and Ireland } \\
\text { yearly human } \\
\text { population }\end{array}$ & $\begin{array}{l}\text { 1913-1922 are figures for England, Wales } \\
\text { and Scotland; from 1922, onwards } \\
\text { Northern Ireland is included }\end{array}$ & Office of National statistics (ONS) \\
\hline
\end{tabular}

1079

1080

1081 


\begin{tabular}{llll}
\hline s(Storms) & $<0.001$ & 0.94 & 6.0 \\
s(Max_K_index) & $<0.001$ & 0.79 & 4.0 \\
s(Max_SST) & 2.40 & $<0.001$ & 9.0 \\
s(NAO_index) & 0.92 & $<0.05$ & 9.0 \\
s(Fish_catch) & 0.79 & 0.02 & 9.0 \\
s(Year, Species) & 103 & $<0.001$ & 210 \\
\hline
\end{tabular}

1082 Table 2 Generalized additive model (GAM) outputs from a model of correlates of strandings

1083 for the UK and Ireland, from 1913-2015. s() are smooths of the explanatory variables.

1084 'Storms' refer to the storm count for each year, 'Max_K_Index' is the geomagnetic reading

1085 (where the K-index is used to characterize the magnitude of geomagnetic storms),

1086 'Max_SST' is the yearly maximum sea surface temperature $\left({ }^{\circ} \mathrm{C}\right)$, 'NAO_index' is the North

1087 Atlantic Oscillation which is the difference of normalized sea level pressure (SLP) between

1088 Stykkisholmur/Reykjavik, Iceland, and Lisbon, Portugal, 'Fish_catch' is annual fish catch

1089 (1,000 tons) for the UK and Ireland, 'Year' is the years 1913-2015, 'Species' are the 21

1090 cetacean species that make up the data set. This table shows the estimated degrees of

1091 freedom (EDF) for each of the different predictor variables. The $P$-values show whether the

1092 smooth of that variable is significantly different from "no effect", i.e., if we estimated the

1093 smooth as a flat line at zero. $\mathrm{k}$ shows the maximum basis complexity. 
1094

a)

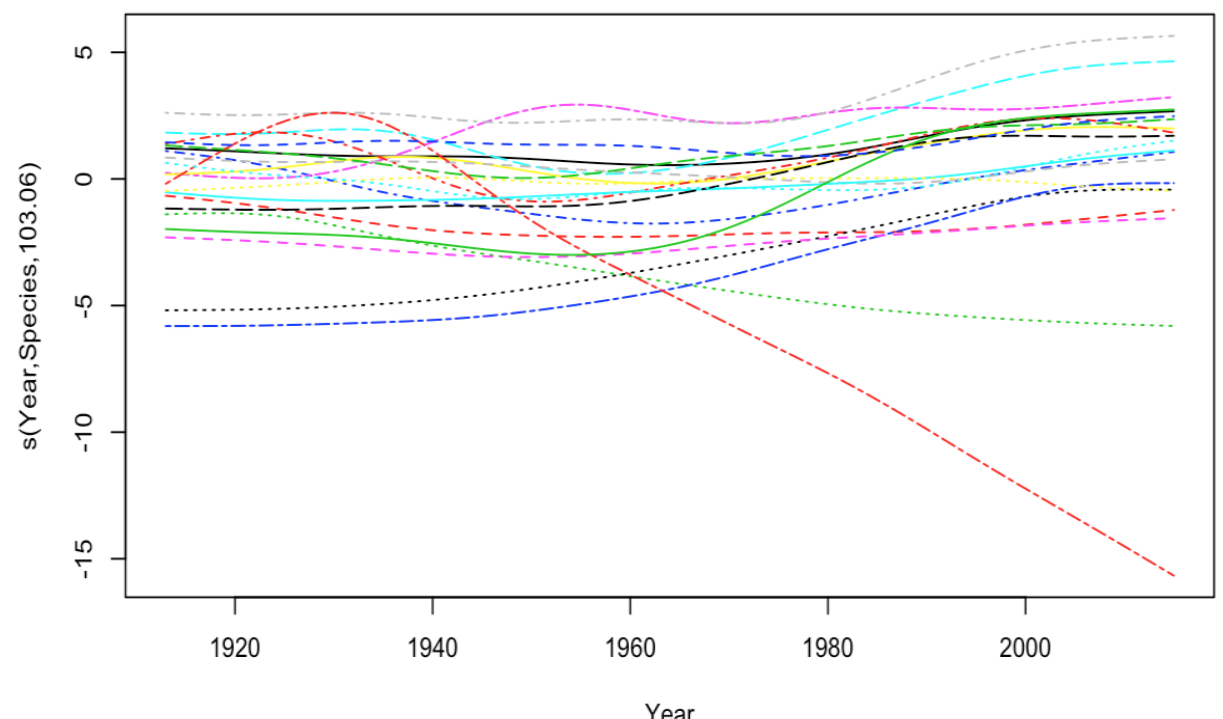

1095

1096

c)

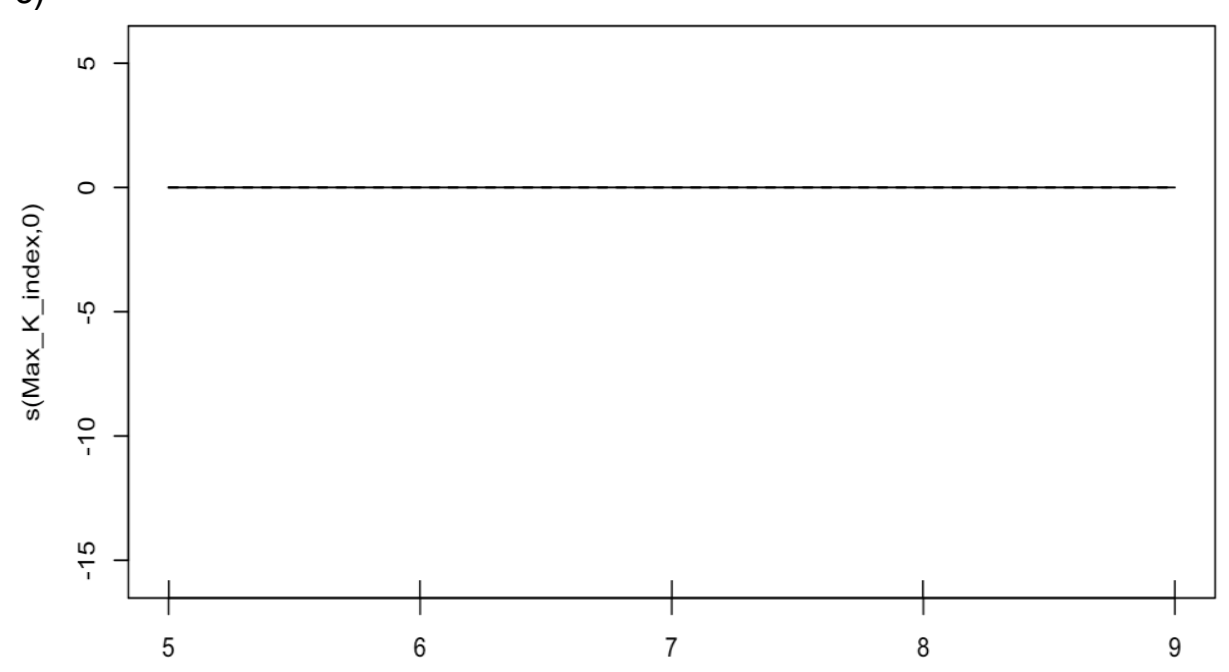

1097 b)

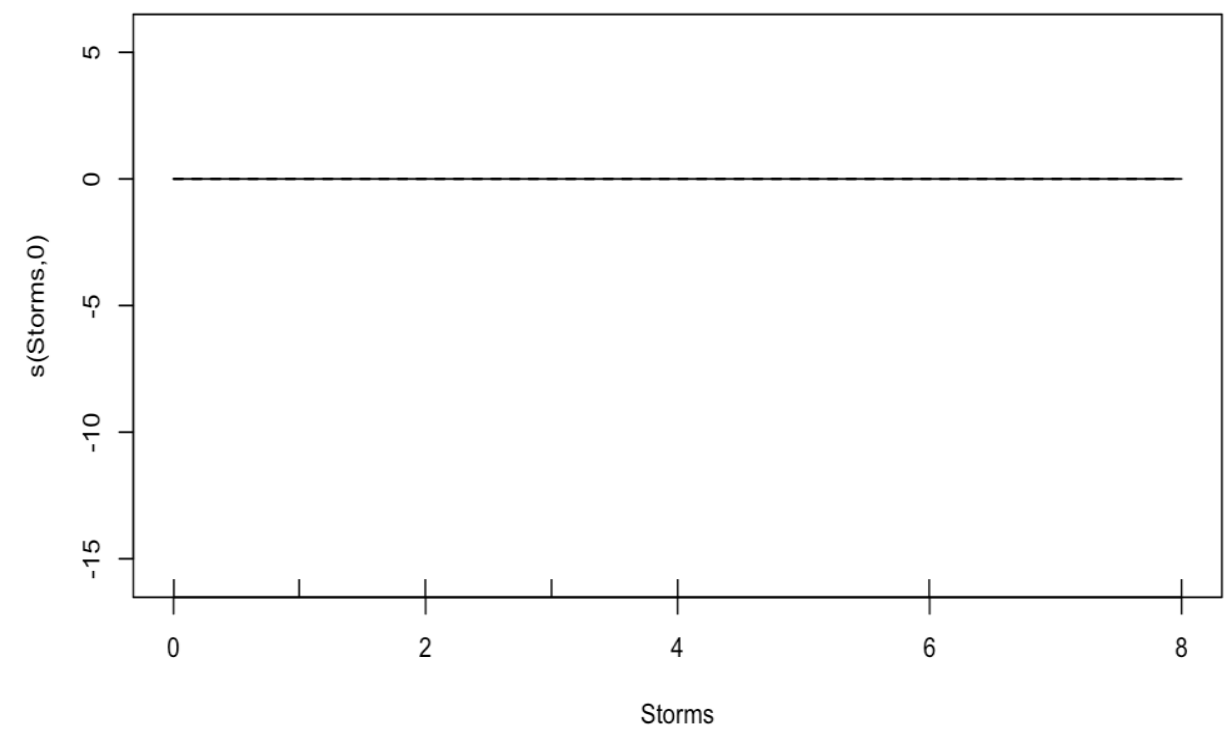

d)

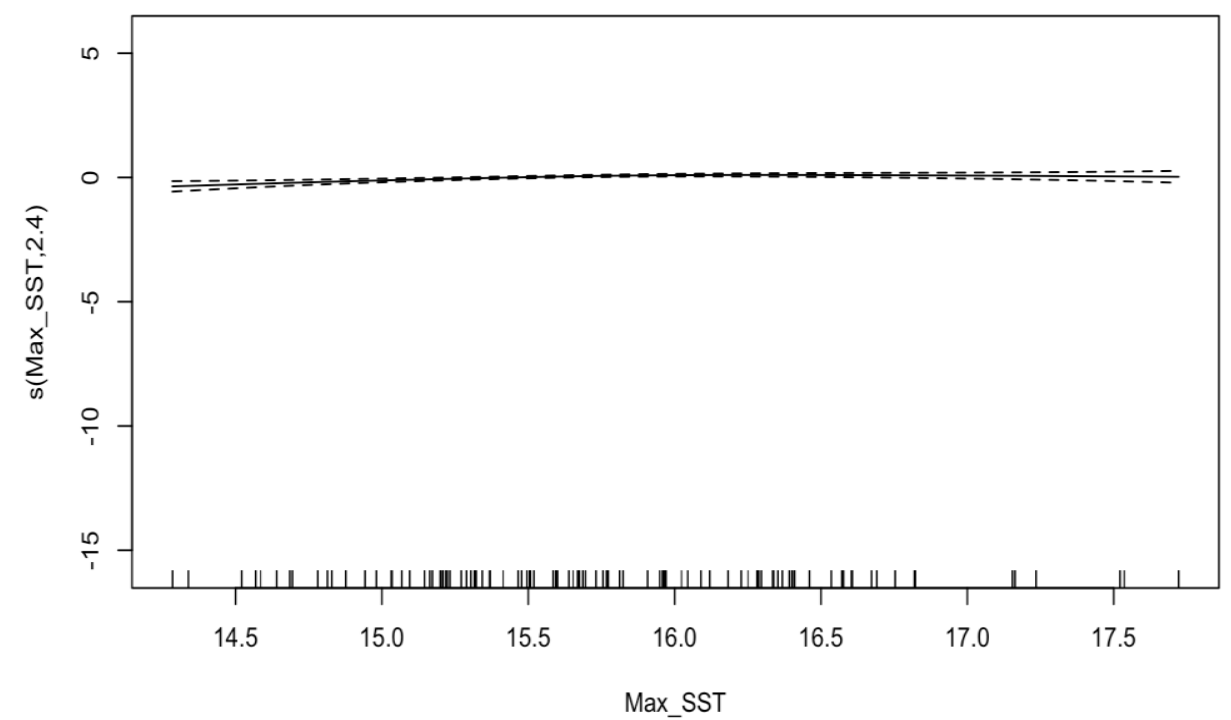


1098

1099

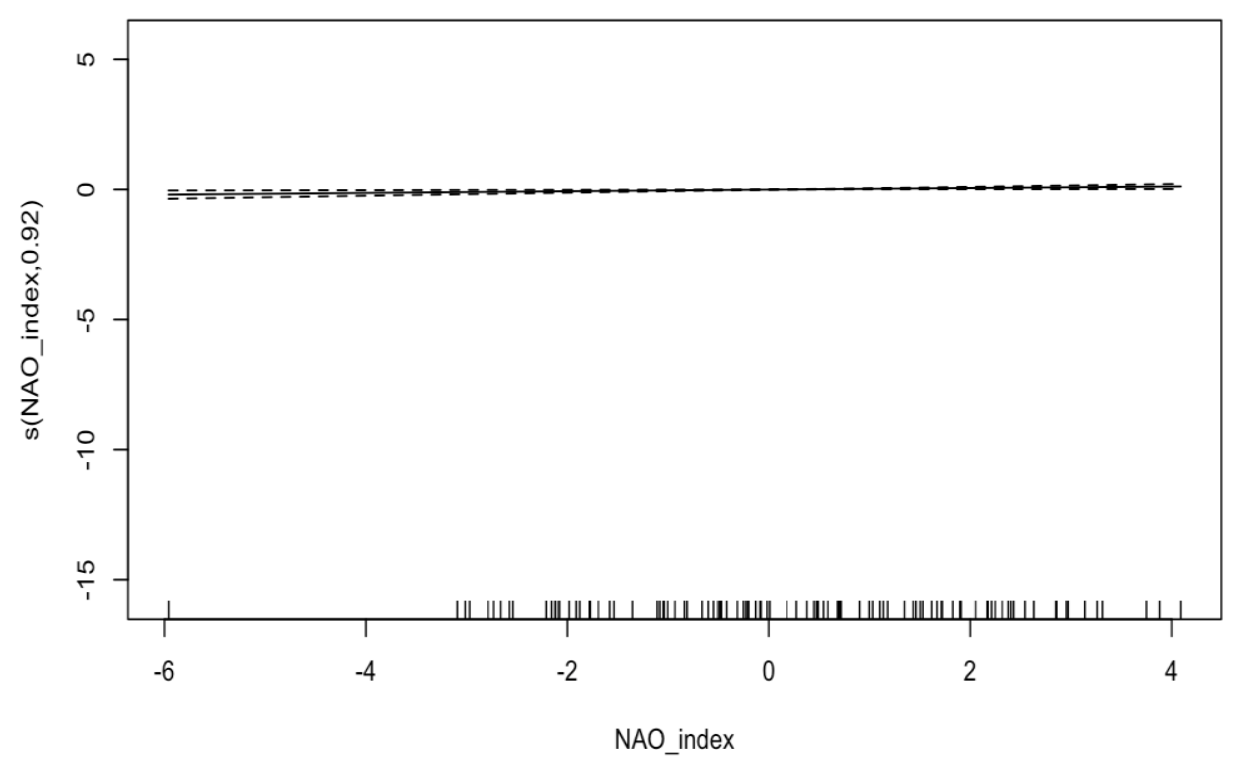

f)

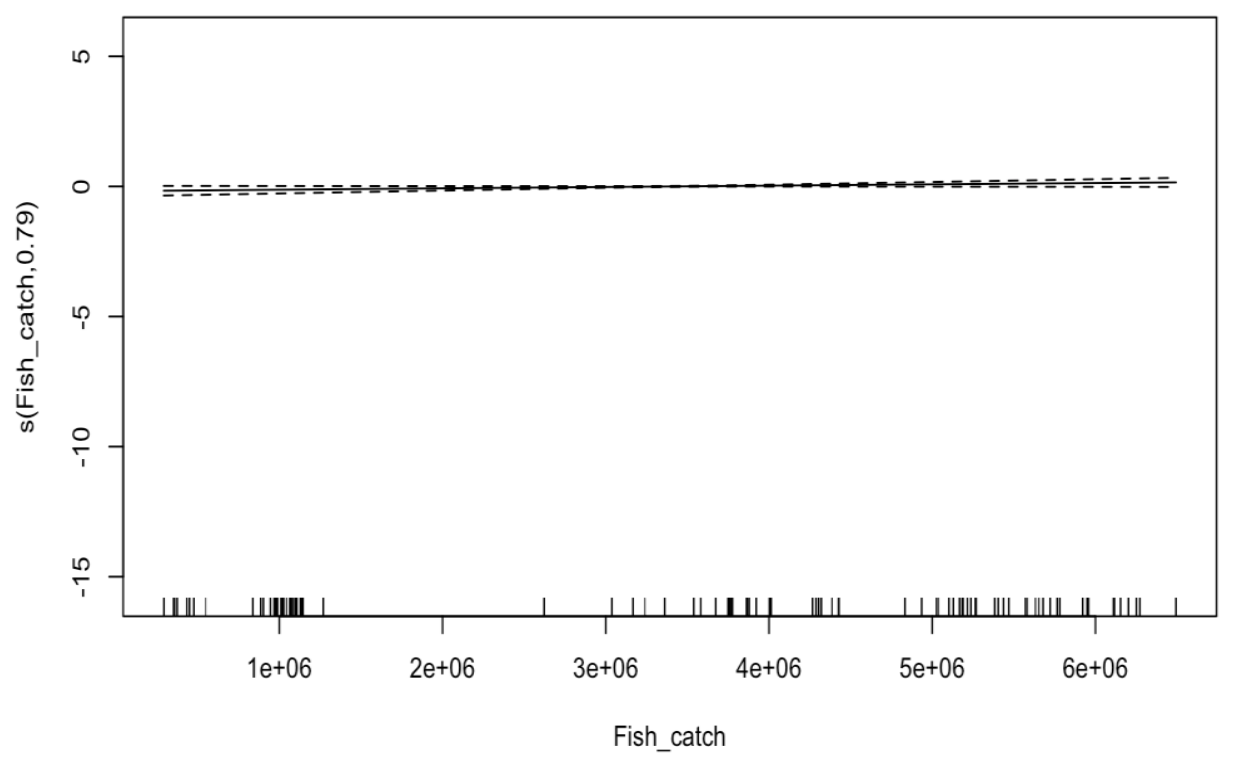


1101 Figure 6. Generalized Additive Model (GAM) summary plots for variables included in the

1102 final model of correlates of cetacean strandings; a) Year, Species smooth, b) Storm events

$1103 \mathrm{~s}($ Storms), c) Geomagnetic index, s(Max_K_index), d) Maximum sea surface temperatures,

1104 s(Max_SST), e) North Atlantic Oscillation index, s(NAO_index), f) Annual fishing catch,

$1105 \mathrm{~s}$ (Fish_catch). X-axis shows the values for that variable (i.e., the year 1913-2015 (a), storm

1106 counts (b), maximum k-index value (c), Maximum sea surface temperature $\left({ }^{\circ} \mathrm{C}\right)(\mathrm{d})$, NAO

1107 index value (e), and fishing catch (1,000 tons) (f). The $y$-axis shows the smooth and the

1108 estimated degrees of freedom (EDF) (e.g., s(Max_SST, 2.4). These EDF values are also

1109 reported in Table 2. Modelled using the negative binomial response count distribution. The

1110 model has a deviance explained of $84.5 \%, n=2163$. 
1111 Table 3. Generalized additive model (GAM) outputs from additional models. '1990s model' is

1112 correlates of stranding GAM using only CSIP and IWDG stranding data (1990 - 2015).

1113 'Regional model 1' is correlates of stranding GAM using data from the south west of the UK.

1114 'Regional model 2' is correlates of stranding GAM using data from the north west of the UK.

$1115 \mathrm{~s}()$ are smooths of the explanatory variables. 'Storms' refer to the storm count for each year,

1116 'Max_K_Index' is the geomagnetic reading (where the K-index is used to characterize the

1117 magnitude of geomagnetic storms), 'Max_SST' is the yearly maximum sea surface

1118 temperature $\left({ }^{\circ} \mathrm{C}\right)$, 'NAO_index' is the North Atlantic Oscillation which is the difference of

1119 normalized sea level pressure (SLP) between Stykkisholmur/Reykjavik, Iceland, and Lisbon,

1120 Portugal, 'Fish_catch' is annual fish catch (1,000 tons) for the UK and Ireland, 'Year' is the

1121 years 1990-2015 in the 1990s model, and 1991-2015 in the Regional models. 'Ships_tons' is

1122 the combined yearly weight of ships over 500 tons in the UK, as a proxy for ship strike.

1123 'Species' are the cetacean species that make up the strandings dataset. This table shows

1124 the estimated degrees of freedom (EDF) for each of the different variables. The $P$-values

1125 show whether the smooth of that variable is significantly different from "no effect", i.e., if we

1126 estimated the smooth as a flat line at zero.

\begin{tabular}{llll}
\hline $\begin{array}{l}\text { Correlates as } \\
\text { modelled }\end{array}$ & 1990s model & Regional model 1 & Regional model 2 \\
\hline $\mathrm{s}$ (Storms) & $0.79^{*}$ & $0.93^{*}$ & $0.81^{*}$ \\
$\mathrm{~s}($ Max_K_index) & 0.38 & $<0.001$ & 0.12 \\
$\mathrm{~s}($ Max_SST) & $<0.001$ & $<0.001$ & $<0.001$ \\
$\mathrm{~s}(\mathrm{NAO}$ index) & $1.36^{* *}$ & $6.62^{* *}$ & $1.11^{* *}$ \\
$\mathrm{~s}($ Fish_catch) & $0.79^{*}$ & $3.95^{* *}$ & $2.38^{* *}$ \\
$\mathrm{~S}($ Ships_tons) & $1.13^{* *}$ & $4.40^{* *}$ & $1.07^{* *}$ \\
$\mathrm{~s}($ Year, Species) & $43.0^{* *}$ & $40.1^{* *}$ & $25.5^{* *}$
\end{tabular}




\begin{tabular}{|c|c|c|c|c|c|c|c|c|c|c|c|c|c|c|c|c|c|c|}
\hline \multirow[b]{2}{*}{ Species } & \multicolumn{3}{|c|}{ Year } & \multicolumn{3}{|c|}{ Storms } & \multicolumn{2}{|c|}{$\begin{array}{l}\text { Geomagnetic k- } \\
\text { index }\end{array}$} & \multicolumn{4}{|c|}{ Maximum SST $\left({ }^{\circ} \mathrm{C}\right)$} & \multicolumn{3}{|c|}{ NAO index } & \multicolumn{3}{|c|}{ Fishing catch } \\
\hline & EDF & $P$-value & $\mathrm{k}$ & EDF & $P$-value & $\mathrm{k}$ & EDF & $P$-value & $\mathrm{k}$ & EDF & $P$-value & $\mathrm{k}$ & EDF & $P$-value & $\mathrm{k}$ & EDF & $P$-value & $\mathrm{k}$ \\
\hline Balaenoptera acutorostrata & 4.98 & $<0.001$ & 9 & 0.51 & 0.14 & 4 & 0.23 & 0.25 & 3 & 0.71 & 0.06 & 9 & $<0.001$ & 0.96 & 9 & 0.79 & 0.02 & 9 \\
\hline Balaenoptera physalus & 3.57 & $<0.001$ & 9 & 0.94 & $<0.005$ & 4 & 0.58 & 0.13 & 3 & $<0.001$ & 0.58 & 9 & 0.93 & $<0.005$ & 9 & 0.79 & 0.02 & 9 \\
\hline Delphinus delphis & 7.03 & $<0.001$ & 9 & 0.58 & 0.11 & 4 & 0.87 & 0.02 & 3 & $<0.005$ & 0.48 & 9 & 0.13 & 0.30 & 9 & 0.84 & 0.01 & 9 \\
\hline Globicephala melas & $<0.001$ & 0.93 & 9 & $<0.001$ & 0.86 & 4 & $<0.001$ & 1.00 & 3 & 1.02 & $<0.001$ & 9 & $<0.001$ & 0.76 & 9 & 0.67 & $<0.001$ & 9 \\
\hline Grampus griseus & 56.3 & $<0.001$ & 9 & $<0.001$ & 0.53 & 4 & 0.84 & 0.02 & 3 & $<0.001$ & 0.56 & 9 & $<0.001$ & 0.18 & 9 & 0.66 & 0.05 & 9 \\
\hline Hyperoodon ampullatus & $<0.001$ & 0.95 & 9 & 0.36 & 0.22 & 4 & 1.03 & $<0.001$ & 3 & $<0.001$ & 0.33 & 9 & $<0.001$ & 0.43 & 9 & $<0.001$ & 0.59 & 9 \\
\hline Lagenorhynchus acutus & 7.21 & $<0.001$ & 9 & 0.50 & 0.16 & 4 & $<0.001$ & 0.21 & 3 & $<0.001$ & 0.91 & 9 & $<0.001$ & 0.60 & 9 & $<0.001$ & 0.59 & 9 \\
\hline Lagenorhynchus albirostris & 3.70 & $<0.001$ & 9 & $<0.001$ & 0.57 & 4 & 0.14 & 0.28 & 3 & $<0.001$ & 0.77 & 9 & $<0.001$ & 0.82 & 9 & 0.61 & 0.08 & 9 \\
\hline Mesoplodon bidens & 1.20 & $<0.001$ & 9 & $<0.001$ & 0.46 & 4 & $<0.001$ & 0.66 & 3 & $<0.001$ & 0.54 & 9 & $<0.001$ & 0.09 & 9 & $<0.001$ & 0.40 & 9 \\
\hline Orcinus orca & 0.64 & 0.10 & 9 & 0.75 & 0.05 & 4 & $<0.001$ & 0.47 & 3 & $<0.001$ & 0.38 & 9 & $<0.001$ & 0.80 & 9 & $<0.001$ & 0.76 & 9 \\
\hline Phocoena phocoena & 8.27 & $<0.001$ & 9 & 0.74 & 0.05 & 4 & $<0.005$ & 0.67 & 3 & 0.89 & 0.01 & 9 & 0.04 & 0.32 & 9 & 0.39 & 0.19 & 9 \\
\hline Physeter macrocephalus & 4.19 & $<0.001$ & 9 & 0.71 & 0.05 & 4 & $<0.001$ & 0.80 & 3 & $<0.001$ & 0.44 & 9 & $<0.005$ & 0.31 & 9 & $<0.001$ & 0.75 & 9 \\
\hline Pseudorca crassidens & 1.04 & 0.05 & 9 & $<0.001$ & 0.88 & 4 & $<0.001$ & 0.46 & 3 & 0.99 & 0.07 & 9 & $<0.001$ & 0.76 & 9 & $<0.001$ & 0.93 & 9 \\
\hline Stenella coeruleoalba & 5.45 & $<0.001$ & 9 & $<0.001$ & 0.89 & 4 & $<0.001$ & 0.83 & 3 & $<0.001$ & 0.75 & 9 & 0.76 & 0.05 & 9 & 0.18 & 0.24 & 9 \\
\hline Tursiops truncatus & 3.54 & 0.001 & 9 & $<0.001$ & 0.92 & 4 & $<0.001$ & 0.90 & 3 & $<0.001$ & 0.77 & 9 & $<0.001$ & 0.79 & 9 & $<0.001$ & 0.79 & 9 \\
\hline Ziphius cavirostris & 2.70 & 0.001 & 9 & $<0.001$ & 0.95 & 4 & $<0.001$ & 1.00 & 3 & $<0.001$ & 1.00 & 9 & $<0.001$ & 0.45 & 9 & $<0.001$ & 0.76 & 9 \\
\hline
\end{tabular}

1128 Table 4. Generalized additive model (GAM) outputs from a model of correlates of strandings for the UK and Ireland, from 1913-2015 for each

1129 individual species. 'Storms' refer to the storm count for each year, 'Geomagnetic k-index' is the geomagnetic reading (where the K-index is

1130 used to characterize the magnitude of geomagnetic storms), 'Maximum SST' is the yearly mean maximum sea surface temperature ( $\left.{ }^{\circ} \mathrm{C}\right)$, 'NAO

1131 index' is the North Atlantic Oscillation which is the difference of normalized sea level pressure (SLP) between Stykkisholmur/Reykjavik, Iceland,

1132 and Lisbon, Portugal, Fishing catch' is annual fish catch from the UK and Ireland (1,000 tons), 'Year' is the years 1913-2015, 'Species' are the

113316 cetacean species which had 100 or more strandings in the dataset. Rarer species were removed because they had insufficient data to fit the

1134 models. This table shows the estimated degrees of freedom (EDF) for each of the different predictor variables. The $P$-values show whether the

1135 smooth of that variable is significantly different from "no effect", i.e., if we estimated the smooth as a flat line at zero. k shows the maximum

1136 basis complexity.

1137 